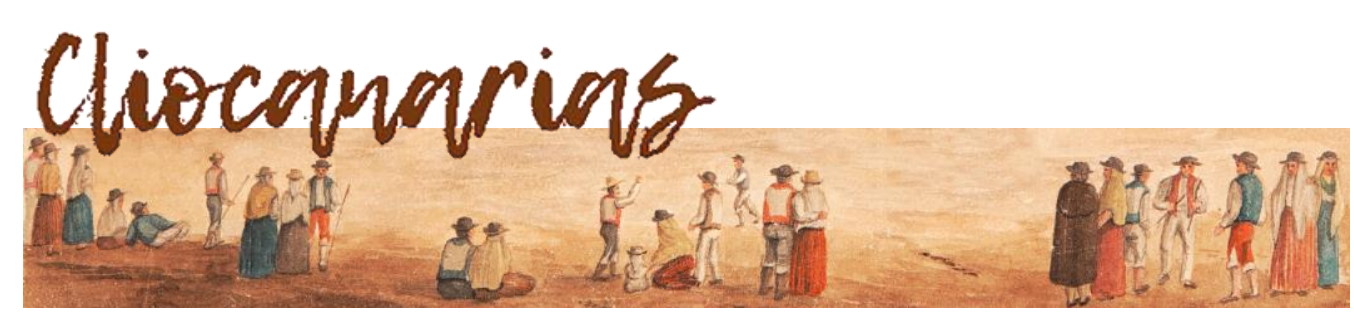

ISSN 2695-4494

https://doi.org/10.53335/cliocanarias.2021.3.24

\title{
APROXIMACIÓN A LA OBRA HEMEROGRÁFICA DE DACIO VICTORIANO DARIAS Y PADRÓN
}

\section{Daniel GARCÍA PULIDO*}

La figura de Dacio Victoriano Darias y Padrón (Valverde, 1880-La Laguna, 1960) ${ }^{1}$ representa, sin duda, uno de los referentes del historicismo regionalista que tuvo su arranque en Canarias en las primeras décadas del siglo XX. Junto a otros intelectuales de su generación, caso de Sebastián Padrón Acosta, Buenaventura Bonnet Reverón y José Peraza de Ayala, entre otros, se distinguió por una perseverante faceta divulgadora al acercar el conocimiento del pasado isleño, en sus diferentes facetas y épocas, a los lectores de la prensa diaria.Darias y Padrón, dentro de la esfera de su preocupación y desvelos por la investigación del pasado de las Islas, aparece no solo en el grupo de estudiosos que dieron inicio a la edición de la primigenia Revista de Historia, en 1926, sino que, casi a renglón seguido, formó parte asimismo en la creación del Instituto de Estudios Canarios. Militar de profesión y con titulación de profesor mercantil y de

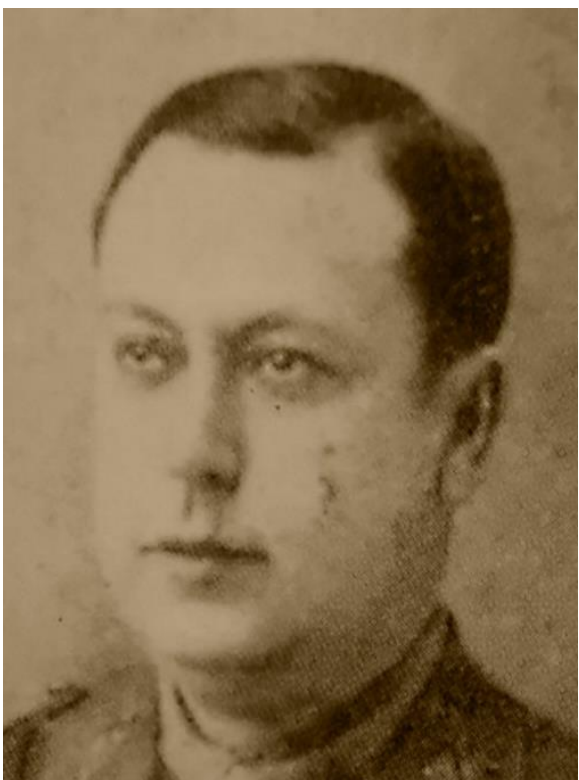

Dacio Victoriano Darias Y Padrón, ca. 1930

(Gran Enciclopedia Canaria) maestro de primera enseñanza, Darias y Padrón se constituye en uno de los paradigmas más significativos del proceso de conformación de los estudios históricos a través del acopio y detenido análisis de la documentación, proceso que acabaría cristalizando años más tarde, merced al apadrinamiento del catedrático Elías Serra Ràfols, en la creación de la ansiada Facultad de Filosofia

\footnotetext{
* Técnico especialista del Fondo de Canarias de la Biblioteca de la Universidad de La Laguna (BULL). C. e.: dgarciap@ull.edu.es

${ }^{1}$ Para su biografia:

-Revista de Historia, XIX, n. ${ }^{\circ} 101 / 104$ (1953), pp. 335-340; y Revista de Historia Canaria, XXVI, n. ${ }^{\circ} 131 / 132$ (1960), pp. 465-471.

-AYALA ZAMORA, José: Datos biográficos de D. Dacio Victoriano Darias y Padrón, 18801960: herreño, militar, maestro, historiador, Cabildo Insular de El Hierro, Valverde, 1999.

-MONTERO HERRERO, Emilio: biografia en el Diccionario biográfico de la Real Academia de la Historia, 2018 [<http:/ / dbe.rah.es / biografias / 69683/dacio-victoriano-darias-padron>].

-IZQUIERDO PÉREZ, Eliseo: "Don Dacio y Machín, dos cronistas dispares”, en El Día, Santa Cruz de Tenerife, 28 de julio de 2019.
} 
y Letras primero, y en las ramas universitarias especializadas de Arqueología e Historia después.

El repaso de las trayectorias vital e investigadora de Dacio Victoriano Darias nos brinda matices de indudable interés que singularizan a nuestro personaje, entre los cuales queremos enfatizar solo unos pocos. Su nacimiento e infancia en El Hierro, su vecindad en Tenerife o sus largas estancias en varias localidades de Gran Canaria por motivos profesionales le permitieron disponer de recursos y contactos en casi cualquier punto del archipiélago, siendo la voz asidua en la prensa del momento en prácticamente todos los rotativos de las diferentes islas (Tenerife, Gran Canaria, La Gomera, El Hierro). Esta circunstancia no la encontramos en ninguno de sus coetáneos, que de manera preferente se especializaron en un territorio en concreto y centraron sus publicaciones en la prensa de la isla en cuestión. Otro ámbito para nosotros poco conocido sobre Darias y Padrón subyace en la lectura de su larga treintena de textos sobre temas políticos, no exentos de polémicas y enfrentamientos en prensa con personalidades del momento. Mención aparte se merecen sus desvelos por el tema del arbolado y su importancia, por los aspectos industriales y por la calidad de la enseñanza en las Islas.

En esta sección presentamos una recopilación de muchos de sus artículos y colaboraciones en revistas y rotativos de las islas y de la Península, listado que, desde un inicio, hemos de reconocer tan solo como una aproximación a su obra hemerográfica. Las razones que nos impiden ofrecer un resultado más definitivo o globalizador descansan no solo en el carácter prolífico de nuestro autor, con textos publicados en la inmensa mayoria de las ediciones periódicas del momento, sino particularmente en la dificultad de poder acceder a dichas colecciones hemerográficas, inaccesibles en muchas ocasiones a nuestra consulta. Confiamos en que el proceso de digitalización auspiciado desde el Fondo de Canarias, de la Biblioteca de la Universidad de La Laguna, nos ayude a completar en un futuro próximo esa ansiada regesta de los textos de Darias y Padrón. 


\section{Artículos en la PRensa de Dacio Victoriano Darias y PadRón}

"Alrededor de un proyecto", en La Opinión. Santa Cruz de Tenerife, 28 de marzo de 1916. p. 1.

"Una aclaración», en La Opinión. Santa Cruz de Tenerife, 1 de abril de 1916. p. 1 .

"Problemas herreños", en La Opinión. Santa Cruz de Tenerife, 5 de julio de 1916. p. 1.

"Escasez de personal de Correos y Telégrafos en Canarias", en La Opinión. Santa Cruz de Tenerife, 26 de agosto de 1919. p. 1.

"Contestación obligada", en La Opinión. Santa Cruz de Tenerife, 6 de septiembre de 1919. p. 1.

"La fiesta de los Menceyes", en La Opinión. Santa Cruz de Tenerife, 12 de septiembre de 1919. p. 1.

"Deshaciendo equívocos», en El Deber. Valverde, 29 de febrero de 1920. p. 1.

"Trabajo de D. Dacio V. Darias y Padrón, cronista titular de esta villa, que fue leído en el acto de la velada que el Gabinete Instructivo de Valverde celebró el 15 de junio de 1918 (I)", en El Deber. Valverde, 31 de marzo de 1920. p. 1.

"Trabajo de D. Dacio V. Darias y Padrón, cronista titular de esta villa, que fue leído en el acto de la velada que el Gabinete Instructivo de Valverde celebró el 15 de junio de 1918 (II)", en El Deber. Valverde, 30 de abril de 1920. p. 1.

"Trabajo de D. Dacio V. Darias y Padrón, cronista titular de esta villa, que fue leído en el acto de la velada que el Gabinete Instructivo de Valverde celebró el 15 de junio de 1918 (y III)", en El Deber. Valverde, 31 de mayo de 1920. p. 1.

"Los pozos de la isla de El Hierro (I)", en El Deber. Valverde, 30 de septiembre de 1920. p. 1.

"Los pozos de la isla de El Hierro (y II)", en El Deber. Valverde, 30 de octubre de 1920. p. 1 .

"La familia del Virrey de Filipinas", en La Comarca. Icod de los Vinos, 16 de enero de 1921. p. 1.

"E1 doctor Quintero Magdaleno (I)», en El Deber. Valverde, 15 de enero de 1921. p. 2. 
"E1 doctor Quintero Magdaleno (y II)", en El Deber. Valverde, 31 de enero de 1921. p. 2.

"El Hierro frente a la política martinista», en El Progreso. Santa Cruz de Tenerife, 2 de febrero de 1921. p. 1.

"Los Méndez y Espinosas (I)", en La Comarca. Icod de los Vinos, 13 de marzo de 1921. pp. 2-3.

"Los Méndez y Espinosas (II)", en La Comarca. Icod de los Vinos, 27 de marzo de 1921. p. 2 .

"Los Méndez y Espinosas (y III)", en La Comarca. Icod de los Vinos, 3 de abril de 1921. p. 1.

"El virrey Quintero de Núñez (I)", en La Comarca. Icod de los Vinos, 30 de abril de 1921. p. 2.

"El virrey Quintero de Núñez (y II)", en La Comarca. Icod de los Vinos, 8 de mayo de 1921. p. 2.

"Glosas de la vida municipal», en El Deber. Valverde, 9 de mayo de 1921. p. 1. "Apostillas a la historia regional. La fundación de Agulo", en El Ideal Lagunero. La Laguna, 28 de mayo de 1921. p. 1

"Apostillas a la historia regional. La fundación de Agulo (La Gomera)", en La Comarca. La Laguna, 5 de junio de 1921. p. 1

"La Virgen de los Reyes y el voto", en El Deber. Valverde, 9 de junio de 1921. p. 1.

"La sequía y el arbolado", en El Deber. Valverde, 9 de agosto de 1921. p. 1.

"La cuna del virrey", en El Ideal Lagunero. La Laguna, 29 de agosto de 1921. p. 2

"La Torre del Conde", en La Voz de Junonia. La Laguna, 27 de noviembre de 1921. pp. 1-2.

"Cartas a El Hierro. Impresiones del momento", en El Deber. Valverde, 2 de abril de 1922. p. 2.

"El ocaso de una politica nefasta", en El Deber. Valverde, 5 de mayo de 1922. p. 2.

"La moral como factor dirigente de los pueblos", en La Voz de Junonia. La Laguna, 24 de mayo de 1922. p. 1. 
"Más fraternidad y menos política", en El Deber. Valverde, 5 de junio de 1922. p. 1 .

"Bartolomé García del Castillo (I)", en La Comarca. Icod de los Vinos, 11 de junio de 1922. p. 3.

"Bartolomé García del Castillo (II)", en La Comarca. Icod de los Vinos, 18 de junio de 1922. p. 3.

"Bartolomé García del Castillo (y III)", en La Comarca. Icod de los Vinos, 25 de junio de 1922. p. 2.

«El motín de 1762 (I)», en La Voz de Junonia. La Laguna, 16 de agosto de 1922. p. 1.

"El motín de 1762 (II)", en La Voz de Junonia. La Laguna, 23 de agosto de 1922. p. 2.

"El motín de 1762 (y III)", en La Voz de Junonia. La Laguna, 1 de septiembre de 1922. p. 1.

"El balcón de Jinama", en La Voz de Junonia. La Laguna, 4 de diciembre de 1922. p. 1.

"La repoblación de nuestros montes (I)", en El Deber. Valverde, 5 de diciembre de 1922. p. 1.

"El doctor Torres Padilla (I)", en La Voz de Junonia. La Laguna, 9 de diciembre de 1922. p. 1.

"El doctor Torres Padilla (y II)", en La Voz de Junonia. La Laguna, 16 de diciembre de 1922. p. 1.

"Los empachos de indianismo", en El Deber. Valverde, 5 de febrero de 1923. p. 1.

"La historia se repite», en El Deber. Valverde, 15 de marzo de 1923. pp. 1-2.

"Colón y el histórico puerto de San Sebastián", en Gaceta de Tenerife. Santa Cruz de Tenerife, 20 de marzo de 1923. p. 1.

"Responsabilidad moral de maestros y autoridades", en La Voz de Junonia. La Laguna, 24 de marzo de 1923. p. 1.

"Un aniversario glorioso, 1493-1923", en Gaceta de Tenerife. Santa Cruz de Tenerife, 3 de mayo de 1923. p. 1.

"Un aniversario glorioso", en La Comarca. Icod de los Vinos, 6 de mayo de 1923. pp. 1-2. 
"Colón y el histórico puerto de San Sebastián", La Voz de Junonia. La Laguna, 18 de junio de 1923. p. 1.

"Colón y el histórico puerto de San Sebastián (I)", en La Comarca. Icod de los Vinos, 24 de junio de 1923. pp. 1-2.

«Los previsores del porvenir», en El Deber. Valverde, 27 de junio de 1923. p. 1.

"Colón y el histórico puerto de San Sebastián (y II)", en La Comarca. Icod de los Vinos, 1 de julio de 1923. p. 1.

"El convento dominicano de San Pedro Apóstol de Hermigua (I)", en Gaceta de Tenerife. Santa Cruz de Tenerife, 19 de julio de 1923. p. 1.

"El convento de San Pedro Apóstol de Hermigua (II)", en Gaceta de Tenerife. Santa Cruz de Tenerife, 20 de julio de 1923. p. 1.

"El convento de San Pedro Apóstol de Hermigua (y III)", en Gaceta de Tenerife. Santa Cruz de Tenerife, 21 de julio de 1923. p. 1.

"El convento de San Pedro Apóstol de Hermigua (I)", en La Voz de Junonia. La Laguna, 24 de julio de 1923. p. 1.

"El veinticinco de Julio", en Gaceta de Tenerife. Santa Cruz de Tenerife, 25 de julio de 1923. p. 1.

"Recuerdos históricos, el pasado y el presente (I)", en El Deber. Valverde, 27 de julio de 1923. pp. 1-2.

"Recuerdos históricos, el pasado y el presente (y II)", en El Deber. Valverde, 15 de agosto de 1923. pp. 1-2.

"El convento de San Pedro Apóstol de Hermigua (II)", en La Voz de Junonia. La Laguna, 11 de agosto de 1923. p. 1.

"El convento de San Pedro Apóstol de Hermigua (y III)", en La Voz de Junonia. La Laguna, 25 de agosto de 1923. pp. 1-2.

"El Santo Cristo de La Laguna", en Gaceta de Tenerife. Santa Cruz de Tenerife, 14 de septiembre de 1923. p. 1.

"La nueva aurora», en El Deber. Valverde, 27 de octubre de 1923. p. 1.

"El general Dávila Orejón», en La Voz de Junonia. La Laguna, 12 de noviembre de 1923. p. 1.

"Los pobladores de Taganana", en Gaceta de Tenerife. Santa Cruz de Tenerife, 21 de diciembre de 1923. p. 1. 
"La casa de Castro-Chirino", en Revista de Historia. La Laguna: Universidad. I(1), pp. 19-28.

"La Torre del Conde», en Revista de Historia. La Laguna: Universidad. I(2), pp. 41-45.

"El licenciado Tabares de Cala", en Revista de Historia. La Laguna: Universidad. I(3), pp. 49-52.

"El Árbol Santo de la isla de El Hierro (I)", en Revista de Historia. La Laguna: Universidad. I(4), pp. 124-128.

"La reparación de un olvido", en El Deber. Valverde, 15 de febrero de 1924. p. 1.

"Ruegos patrióticos", en Gaceta de Tenerife. Santa Cruz de Tenerife, 27 de febrero de 1924. p. 1.

"El castillo de San Cristóbal", en Gaceta de Tenerife. Santa Cruz de Tenerife, 28 de marzo de 1924. p. 1.

"Cultivos industriales", en El Deber. Valverde, 15 de agosto de 1924. pp. 4-5.

"El marqués de Bajamar", en Revista de Historia. La Laguna: Universidad. I(5), pp. 152-155.

"Los repartos del Adelantado (I)", en Revista de Historia. La Laguna: Universidad. I(5), pp. 186-288.

"E1 Árbol Santo de la isla de El Hierro (y II)", en Revista de Historia. La Laguna: Universidad. I(6), pp. 189-192.

"El almirante Nava y Porlier", en Revista de Historia. La Laguna: Universidad. I(6), pp. 213-215.

"Los repartos del Adelantado (II)", en Revista de Historia. La Laguna: Universidad. I(6), pp. 222-224.

"Los repartos del Adelantado (y III)", Revista de Historia. La Laguna: Universidad. I(7), pp. 249-251.

"Don Aquilino Padrón y Padrón", en Revista de Historia. La Laguna. I(8), pp. 252-254.

"Un cuadro estimable", en Gaceta de Tenerife. Santa Cruz de Tenerife, 30 de abril de 1925. p. 1.

"Felipe II y su tiempo", en Gaceta de Tenerife. Santa Cruz de Tenerife, 12 de septiembre de 1925. p. 1. 
"A propósito de una honrosa alusión", en Gaceta de Tenerife. Santa Cruz de Tenerife, 19 de septiembre de 1925. p. 1.

"Necesidad de una buena cultura primaria", en Gaceta de Tenerife. Santa Cruz de Tenerife, 26 de septiembre de 1925. p. 1.

"La construcción de grupos escolares", en Gaceta de Tenerife. Santa Cruz de Tenerife, 20 de octubre de 1925. p. 1.

"El estatuto de la enseñanza mercantil», en Gaceta de Tenerife. Santa Cruz de Tenerife, 22 de diciembre de 1925. p. 1.

"Ramas de arqueología. Nuestras antiguas indumentarias (I)", en Revista de Historia. La Laguna: Universidad. II(9), pp. 26-29.

"Las milicias de Canarias", en Revista de Historia. La Laguna: Universidad. II(10), pp. 58-60.

"Pedro Quintero de Núñez", en Revista de Historia. La Laguna: Universidad. II(10), pp. 61-64.

"El arte en nuestras iglesias. Algunas imágenes de la parroquial de Valverde», en Revista de Historia. La Laguna: Universidad. II(11), pp. 92-96.

"Ramas de arqueologia. Nuestras antiguas indumentarias (y II)", en Revista de Historia. La Laguna: Universidad. II(12), pp. 116-123.

[1926] Herreños notables. Don Aquilino Padrón y Padrón, en El Deber. Valverde, 1 de marzo de 1926. pp. 1-2.

"A propósito de la futura Exposición Iberoamericana", Gaceta de Tenerife. Santa Cruz de Tenerife, 12 de marzo de 1926. p. 1.

"Yo creo...", en Gaceta de Tenerife. Santa Cruz de Tenerife, 1 de abril de 1926. p. 3.

"La isla de La Gomera, sus tradiciones y su riqueza. Sus rasgos históricos", en La Prensa. Santa Cruz de Tenerife, 9 de mayo de 1926. pp. 1 y 3.

"Canarios en Indias. Pedro Quintero de Núñez (I)", en El Deber. Valverde, 15 de julio de 1926. pp. 1-2.

"Canarios en Indias. Pedro Quintero de Núñez (y II)", en El Deber. Valverde, 1 de agosto de 1926. pp. 1-2.

"Rápidas impresiones de un viajero (I)", en Gaceta de Tenerife. Santa Cruz de Tenerife, 3 de octubre de 1926. p. 1.

"Rápidas impresiones de un viajero (y II)", en Gaceta de Tenerife. Santa Cruz 
de Tenerife, 6 de octubre de 1926. p. 1.

"Magna domus", en Gaceta de Tenerife. Santa Cruz de Tenerife, 12 de octubre de 1926. p. 3.

"La conferencia imperial británica", en Gaceta de Tenerife. Santa Cruz de Tenerife, 3 de noviembre de 1926. p. 1.

"La repoblación forestal", en Las Noticias. Santa Cruz de Tenerife, 23 de noviembre de 1926. p. 1.

"Ataquemos el analfabetismo", en Las Noticias. Santa Cruz de Tenerife, 14 de diciembre de 1926. p. 1.

"El general Ludendorff", en Las Noticias. Santa Cruz de Tenerife, 18 de diciembre de 1926. p. 1.

"San Agustín, patrón de la isla de El Hierro", en Revista de Historia. La Laguna: Universidad. II(13), pp. 158-162.

"El licenciado Bueno", en Revista de Historia. La Laguna: Universidad. II(14/15), pp. 207-212.

"El historiador Anchieta y Alarcón", en Revista de Historia. La Laguna: Universidad. IV(16), pp. 253-258.

"En el tercer cincuentenario de la Real Sociedad Económica [I]", en Las Noticias. La Laguna, 18 de febrero de 1927. p. 1.

"En el tercer cincuentenario de la Real Sociedad Económica [y II]", en Las Noticias. La Laguna, 19 de febrero de 1927. p. 1.

"Pedro Quintero de Núñez», en Las Noticias. La Laguna, 25 de febrero de 1927. p. 3.

"E1 marqués de Bajamar», en Las Noticias. La Laguna, 9 de marzo de 1927. p. 4.

"La riqueza del subsuelo inglés [traducción]", en Las Noticias. La Laguna, 22 de marzo de 1927. p. 1.

"Plano de la isla de El Hierro", en Las Noticias. La Laguna, 6 de abril de 1927. p. 1.

"El almirante Nava y Porlier", en Las Noticias. La Laguna, 12 de abril de 1927. p. 3.

"En la villa de San Miguel de Teguise», en Las Noticias. Santa Cruz de Tenerife, 29 de abril de 1927. p. 1. 
"El arbolado y su necesidad (II)", en Las Noticias. Santa Cruz de Tenerife, 6 de mayo de 1927. p. 1.

"El arbolado y su necesidad (y IV)", en Las Noticias. Santa Cruz de Tenerife, 14 de mayo de 1927. p. 1.

"La realeza de los borbones", en Las Noticias. La Laguna, 17 de mayo de 1927. p. 1.

"La futura exposición regional de industrias", en Las Noticias. La Laguna, 4 de junio de 1927. p. 1.

"Ramas de arqueología. Nuestras antiguas indumentarias (I)", en Las Noticias. La Laguna, 6 de junio de 1927. p. 1.

"El antiguo problema de las aguas", en Las Noticias. Santa Cruz de Tenerife, 9 de julio de 1927. p. 1.

"El triunfo de un universitario", en Las Noticias. La Laguna, 10 de agosto de 1927.

"La Torre del Conde", en Las Noticias. La Laguna, 17 de noviembre de 1927. p. 3.

"El origen de la villa de La Orotava y de su puerto (I)", en Revista de Historia. La Laguna: Universidad. III(18), pp. 51-55.

"El origen de la villa de La Orotava y de su puerto (II)", en Revista de Historia. La Laguna: Universidad. III(19), pp. 78-82.

"La nueva villa de Güímar", en Revista de Historia. La Laguna: Universidad. III(19), pp. 88-90.

"El origen de la villa de La Orotava y de su puerto (III)", en Revista de Historia. La Laguna: Universidad. III(20), pp. 97-103.

"Laguneros ilustres. El arzobispo Bencomo", en Las Noticias. La Laguna, 5 de marzo de 1928. p. 3.

"Orotavenses ilustres. E1 historiador Anchieta y Alarcón", en Las Noticias. La Laguna, 23 de abril de 1928. pp. 1-2.

"Breve reseña histórica de la Ilustre Esclavitud de San Juan Evangelista y Santísima Resurrección de Cristo Nuestro Redentor", Revista de Historia y Genealogía Española. Madrid: C. Bermejo. 32 p.

"El origen de la villa de La Orotava y de su puerto (IV)", en Revista de Historia. La Laguna: Universidad. III(21), pp. 140-145. 
"Costumbres e ideales de Santa Cruz de Tenerife en el siglo XVIII", en Revista de Historia. La Laguna: Universidad. III(22), pp. 169-180.

"El Congreso de Genealogía, Nobleza y Heráldica: Exposición de Barcelona", en Revista de Historia. La Laguna: Universidad. III(23), pp. 195-196.

"El origen de la villa de La Orotava y de su puerto (y V)", Revista de Historia. La Laguna: Universidad. III(23), pp. 210-213.

"El canónigo Dr. D. Esteban Fernández-Salazar y Frías", en Revista de Historia. La Laguna: Universidad. III(24), pp. 246-251.

"Chasna o Vilaflor (I)", en La Prensa. Santa Cruz de Tenerife, 22 de febrero de 1929. p. 1.

"Chasna o Vilaflor (II)", en La Prensa. Santa Cruz de Tenerife, 23 de febrero de 1929. p. 1.

"Chasna o Vilaflor (y III)", en La Prensa. Santa Cruz de Tenerife, 24 de febrero de 1929. p. 2.

"Granadilla de Abona (I)", en La Prensa. Santa Cruz de Tenerife, 3 de marzo de 1929. p. 1.

"Granadilla de Abona (II)", en La Prensa. Santa Cruz de Tenerife, 5 de marzo de 1929. p. 1.

"Granadilla de Abona (y III)", en La Prensa. Santa Cruz de Tenerife, 6 de marzo de 1929. p. 1.

"Arona y San Miguel», en La Prensa. Santa Cruz de Tenerife, 7 de marzo de 1929. p. 1.

"Arico y Fasnia (I)", en La Prensa. Santa Cruz de Tenerife, 9 de marzo de 1929. p. 1 .

"Arico y Fasnia (II)", en La Prensa. Santa Cruz de Tenerife, 10 de marzo de 1929. p. 1.

"Arico y Fasnia (y III)", en La Prensa. Santa Cruz de Tenerife, 12 de marzo de 1929. p. 2.

"El pueblo de Candelaria», en La Prensa. Santa Cruz de Tenerife, 14 de marzo de 1929. p. 1.

"Villa de La Orotava", en La Prensa. Santa Cruz de Tenerife, 6 de junio de de 1929. p. 5.

"El Congreso de genealogía, nobleza y heráldica», en La Prensa. Santa Cruz de 
Tenerife, 13 de junio de de 1929. p. 2.

"Bibliografia genealógica. Dos obras interesantes", en La Prensa. Santa Cruz de Tenerife, 16 de julio de de 1929. p. 1.

"Memoria sobre la genealogía, nobleza y heráldica de Canarias", en Primer Congreso de Genealogía y Heráldica. Madrid: C.I.A.P.

"Villa y puerto de Garachico (I)", en Revista de Historia. La Laguna: Universidad. IV(25), pp. 11-18.

"Villa y puerto de Garachico (II)", en Revista de Historia. La Laguna. IV(26) pp. 8-12.

«Páginas de la historia tinerfeña. Episodios históricos de la Villa de La Orotava y Puerto de la Cruz. Segunda parte", en Revista de Historia. La Laguna. IV(27) pp. 4-12.

"La tradicional festividad del Corpus", en La Prensa. Santa Cruz de Tenerife, 19 de junio de 1930. p. 1.

"Puerto de Garachico. Algunos detalles de su historia", en La Prensa. Santa Cruz de Tenerife, 10 de agosto de 1930. p. 3.

"El mariscal de campo don Francisco Tomás Morales", en Revista de Historia y Genealogía Española Madrid: C. Bermejo.

"Villa y puerto de Garachico (III)", en Revista de Historia. La Laguna: Universidad. IV(29-30), pp. 35-49.

"Episodios históricos de la villa de La Orotava y el Puerto de la Cruz (II)", en Revista de Historia. La Laguna: Universidad. IV(29/30), pp. 14-31.

"Los antiguos castellanos del desaparecido castillo de San Cristóbal (I)", en Revista de Historia. La Laguna: Universidad. IV(29/30), pp. 49-55.

«El significado del viejo blasón. El nobiliario cubano, por el conde de Vallellano", en Revista de Historia. La Laguna: Universidad. IV(29-30), pp. 57-61.

"Los antiguos castellanos del desaparecido castillo de San Cristóbal (y II)", en Revista de Historia. La Laguna: Universidad. IV(31), pp. 90-93.

"Episodios históricos de la villa de La Orotava y el Puerto de la Cruz (III)", en Revista de Historia. La Laguna: Universidad. IV(31), pp. 73-81.

"El licenciado Tabares de Cala", en Las Noticias. La Laguna, 12 de mayo de 1931. p. 3.

"Supresión de una conmemoración gloriosa", en Las Noticias. La Laguna, 28 
de julio de 1931. p. 1.

"Sobre el tema regional canario", en La Prensa. Santa Cruz de Tenerife, 29 de julio de 1931. p. 1.

"Réplica final al señor García Ortega», en La Prensa. Santa Cruz de Tenerife, 6 de septiembre de 1931. p. 1.

"La asamblea general", en Las Noticias. La Laguna, 28 de septiembre de 1931. p. 1 .

"E1 Aeródromo de Los Rodeos", en Las Noticias. La Laguna, 24 de noviembre de 1931. p. 1.

"Villa y puerto de Garachico (IV)", en Revista de Historia. La Laguna: Universidad. V(34), pp. 43-53.

"Episodios históricos de la villa de La Orotava y el Puerto de la Cruz (IV)", en Revista de Historia. La Laguna: Universidad. V(35/36), pp. 65-74.

"Villa y puerto de Garachico (V)", en Revista de Historia. La Laguna: Universidad. V(37), pp. 129-137.

"Episodios históricos de la villa de La Orotava y el Puerto de la Cruz (V)", en Revista de Historia. La Laguna: Universidad. V(39/40), pp. 192-203.

"Bibliografía canaria. Una nueva obra de Millares Carlo", en La Prensa. Santa Cruz de Tenerife, 29 de julio de 1932. p. 1.

"La regionalización de la enseñanza en Canarias (I)", en La Prensa. Santa Cruz de Tenerife, 24 de septiembre de 1932. p. 1.

"La regionalización de la enseñanza en Canarias (y II)", en La Prensa. Santa Cruz de Tenerife, 30 de septiembre de 1932. p. 1.

"Estampas sevillanas. Un cuadro de Zurbarán», en La Prensa. Santa Cruz de Tenerife, 25 de octubre de 1932. p. 1.

"Temas turísticos", en La Prensa. Santa Cruz de Tenerife, 14 de junio de 1933. p. 1.

"Los antiguos gobernadores y capitanes generales de Canarias (I)", en La Prensa. Santa Cruz de Tenerife, 8 de septiembre de 1933.

"Los antiguos gobernadores y capitanes generales de Canarias (II)", en La Prensa. Santa Cruz de Tenerife, 9 de septiembre de 1933.

"Los antiguos gobernadores y capitanes generales de Canarias (y III)", en La Prensa. Santa Cruz de Tenerife, 10 de septiembre de 1933. 
"De bibliografia canaria. Una obra de interés para Tenerife", en La Prensa. Santa Cruz de Tenerife, 19 de octubre de 1933. p. 1.

"Notas históricas sobre los Herreras en Canarias", en El Museo Canario. Las Palmas de Gran Canaria. I(2), pp. 43-77.

"Argote de Molina y Gran Canaria (I)", en Hoy. Las Palmas de Gran Canaria, 24 de junio de 1934. p. 1.

"Las lecturas históricas en nuestras escuelas", en La Prensa. Santa Cruz de Tenerife, 28 de julio de 1934. p. 1.

"La festividad de Candelaria", en Gaceta de Tenerife. Santa Cruz de Tenerife, 15 de agosto de 1934. p. 1.

"De La Laguna artística. Un mediorelieve notable», en La Prensa. Santa Cruz de Tenerife, 19 de agosto de 1934. p. 1.

"El alferazgo mayor de Gran Canaria", en Hoy. Las Palmas de Gran Canaria, 22 de agosto de 1934. p. 1.

"Para un pseudo crítico", en La Prensa. Santa Cruz de Tenerife, 26 de agosto de 1934. p. 1.

"El derrumbe de nuestra civilización", en Gaceta de Tenerife. Santa Cruz de Tenerife, 5 de septiembre de 1934. p. 1.

"Mi réplica final", en La Prensa. Santa Cruz de Tenerife, 14 de septiembre de 1934. p. 1.

"Las necesidades del ruralismo", en Gaceta de Tenerife. Santa Cruz de Tenerife, 28 de septiembre de 1934. p. 1.

"Privilegios de Gran Canaria", en Hoy. Las Palmas de Gran Canaria, 28 de septiembre de 1934. p. 1.

"La portada del antiguo corregimiento", en La Prensa. Santa Cruz de Tenerife, 7 de octubre de 1934. p. 1.

"Familias canarias pobladoras de América", en La Prensa. Santa Cruz de Tenerife, 18 de octubre de 1934. p. 1.

"Volcanes en Lanzarote", en Hoy. Las Palmas de Gran Canaria, 19 de octubre de 1934. p. 1.

"El supuesto clericalismo", en Gaceta de Tenerife. Santa Cruz de Tenerife, 1 de noviembre de 1934. p. 1.

"La enseñanza regional de la Historia», en Hoy. Las Palmas de Gran Canaria, 
6 de noviembre de 1934. p. 1.

"Los males del socialismo español", en Gaceta de Tenerife. Santa Cruz de Tenerife, 18 de noviembre de 1934. p. 1 .

"Arribada de náufragos a Fuerteventura", en Hoy. Las Palmas de Gran Canaria, 18 de noviembre de 1934. p. 1.

"El proceso de Hernán Peraza, señor de La Gomera", en Gaceta de Tenerife. Santa Cruz de Tenerife, 4 de diciembre de 1934. p. 1.

"Insularismo en función de regionalismo", en Hoy. Las Palmas de Gran Canaria, 5 de diciembre de 1934. p. 1.

"Región, sin mengua de lo insular", en Hoy. Las Palmas de Gran Canaria, 11 de diciembre de 1934. p. 1.

"Un manuscrito interesante sobre Canarias (II)", en La Prensa. Santa Cruz de Tenerife, 16 de diciembre de 1934. p. 1.

"La función social de la propiedad", en Gaceta de Tenerife. Santa Cruz de Tenerife, 18 de diciembre de 1934. p. 1.

"La villa de Agüimes y sus alcaldes", en Hoy. Las Palmas de Gran Canaria, 19 de diciembre de 1934. p. 1.

"El manuscrito de los pretendidos capellanes de Bethencourt", en Gaceta de Tenerife. Santa Cruz de Tenerife, 23 de diciembre de 1934. p. 1.

"Un manuscrito interesante sobre Canarias (y III)", en La Prensa. Santa Cruz de Tenerife, 2 de enero de 1935. p. 1.

"La democracia y el pueblo", en Gaceta de Tenerife. Santa Cruz de Tenerife, 10 de enero de 1935. p. 1.

"Las islas menores y el comercio de Indias (I)", en Hoy. Las Palmas de Gran Canaria, 16 de enero de 1935. p. 1.

"El escudo blasón de Canarias", en Gaceta de Tenerife. Santa Cruz de Tenerife, 17 de enero de 1935. p. 1.

"Las islas menores y el comercio de Indias (y II)", en Hoy. Las Palmas de Gran Canaria, 17 de enero de 1935. p. 1.

"Cuestiones de indumentaria típica. El antiguo traje de Gran Canaria", en Hoy. Las Palmas de Gran Canaria, 25 de enero de 1935. p. 1.

"La antigua Efigie de la Candelaria", en Gaceta de Tenerife. Santa Cruz de Tenerife, 2 de febrero de 1935. p. 1. 
"La erupción de un volcán en Fuencaliente", en La Prensa. Santa Cruz de Tenerife, 3 de febrero de 1935. p. 1.

"Indumentarias históricas. El antiguo traje regional», en Hoy. Las Palmas de Gran Canaria, 14 de febrero de 1935. p. 1.

"La función de la aristocracia", en Gaceta de Tenerife. Santa Cruz de Tenerife, 22 de febrero de 1935. p. 1.

"El plano de San Sebastián de La Gomera", en La Gaceta de Tenerife. Santa Cruz de Tenerife, 17 de marzo de 1935. p. 1.

"Recordando al novelista Galdós", en Gaceta de Tenerife. Santa Cruz de Tenerife, 10 de abril de 1935. p. 6.

"Industrias desaparecidas. El horno de vidrio de Icod", en La Prensa. Santa Cruz de Tenerife, 12 de mayo de 1935. p. 1.

"El púlpito de la Catedral», en La Prensa. Santa Cruz de Tenerife, 23 de mayo de 1935. p. 1.

"Conveniencia de la artesania", en Gaceta de Tenerife. Santa Cruz de Tenerife, 26 de mayo de 1935. p. 1.

"La festividad del Corpus (II)", en Gaceta de Tenerife. Santa Cruz de Tenerife, 11 de junio de 1935. pp. 1-2.

"La festividad del Corpus (y III)", en Gaceta de Tenerife. Santa Cruz de Tenerife, 13 de junio de 1935. pp. 1-2.

"Un incidente en el octavario de Corpus", en La Prensa. Santa Cruz de Tenerife, 30 de junio de 1934. p. 9.

"Pretéritas culpas de la politica", en Gaceta de Tenerife. Santa Cruz de Tenerife, 5 de julio de 1935. pp. 1-2.

"El veinticinco de Julio", en Gaceta de Tenerife. Santa Cruz de Tenerife, 25 de julio de 1935. p. 1.

"El antiguo señorío de Adeje (II)", en La Prensa. Santa Cruz de Tenerife, 3 de agosto de 1935. p. 4.

"El antiguo señorío de Adeje (y III)", en La Prensa. Santa Cruz de Tenerife, 4 de agosto de 1935. p. 3.

"Información sobre el Patronato de Canarias", en Gaceta de Tenerife. Santa Cruz de Tenerife, 15 de agosto de 1935. pp. 1-2.

"El antiguo traje de los isleños», en La Prensa. Santa Cruz de Tenerife, 27 de 
septiembre de 1935. p. 1.

"Ficciones y realidades políticas", en Gaceta de Tenerife. Santa Cruz de Tenerife, 10 de noviembre de 1935. pp. 1-2.

"El alferazgo mayor de Tenerife (III)", en Gaceta de Tenerife. Santa Cruz de Tenerife, 3 de diciembre de 1935. pp. 1-2.

"El alferazgo mayor de Tenerife (y IV)", en Gaceta de Tenerife. Santa Cruz de Tenerife, 4 de diciembre de 1935. pp. 1-2.

"La rotulación de las calles", en Gaceta de Tenerife. Santa Cruz de Tenerife, 20 de diciembre de 1935. p. 1.

"Las antiguas calles de La Laguna", en La Prensa. Santa Cruz de Tenerife, 29 de enero de 1936. p. 4.

"El incendio del convento de Candelaria (I)", en Gaceta de Tenerife. Santa Cruz de Tenerife, 16 de febrero de 1936. p. 2.

"El incendio del convento de Candelaria (y II)", en Gaceta de Tenerife. Santa Cruz de Tenerife, 19 de febrero de 1936. p. 1.

"Los condes de La Gomera (marqueses de Adeje, señores de la isla del Hierro, etc.) (I)", en Gaceta de Tenerife. Santa Cruz de Tenerife, 14 de marzo de 1936. p. 3.

"In memoriam. El licenciado Rodríguez Moure», en Hoy. Las Palmas de Gran Canaria, 1 de abril de 1936. p. 1.

«Los condes de La Gomera (marqueses de Adeje, señores de la isla del Hierro, etc.) (II)", en Gaceta de Tenerife. Santa Cruz de Tenerife, 3 de abril de 1936. p. 3.

"Los condes de La Gomera (marqueses de Adeje, señores de la isla del Hierro, etc.) (III)", en Gaceta de Tenerife. Santa Cruz de Tenerife, 5 de abril de 1936. p. 6.

"Los condes de La Gomera (marqueses de Adeje, señores de la isla del Hierro, etc.) (IV)", en Gaceta de Tenerife. Santa Cruz de Tenerife, 7 de abril de 1936. p. 6.

"Los condes de La Gomera (marqueses de Adeje, señores de la isla del Hierro, etc.) (V)", en Gaceta de Tenerife. Santa Cruz de Tenerife, 12 de abril de 1936. p. 6.

"Los condes de La Gomera (marqueses de Adeje, señores de la isla del Hierro, etc.) (VI)", en Gaceta de Tenerife. Santa Cruz de Tenerife, 19 de abril de 1936. p. 3. 
"Los condes de La Gomera (marqueses de Adeje, señores de la isla del Hierro, etc.) (VI)" [repetición por error de impresión previo], en Gaceta de Tenerife. Santa Cruz de Tenerife, 22 de abril de 1936. p. 3.

"Los condes de La Gomera (marqueses de Adeje, señores de la isla del Hierro, etc.) (VII)", en Gaceta de Tenerife. Santa Cruz de Tenerife, 23 de abril de 1936. p. 3.

"Los condes de La Gomera (marqueses de Adeje, señores de la isla del Hierro, etc.) (VIII)", en Gaceta de Tenerife. Santa Cruz de Tenerife, 25 de abril de 1936. p. 3.

"Los condes de La Gomera (marqueses de Adeje, señores de la isla del Hierro, etc.) (IX)", en Gaceta de Tenerife. Santa Cruz de Tenerife, 26 de abril de 1936. p. 3.

"Los condes de La Gomera (marqueses de Adeje, señores de la isla del Hierro, etc.) (X)", en Gaceta de Tenerife. Santa Cruz de Tenerife, 29 de abril de 1936. p. 3.

"Los condes de La Gomera (marqueses de Adeje, señores de la isla del Hierro, etc.) (XI)", en Gaceta de Tenerife. Santa Cruz de Tenerife, 30 de abril de 1936. p. 3.

"Los condes de La Gomera (marqueses de Adeje, señores de la isla del Hierro, etc.) (XII)", en Gaceta de Tenerife. Santa Cruz de Tenerife, 2 de mayo de 1936. p. 3.

"Los condes de La Gomera (marqueses de Adeje, señores de la isla del Hierro, etc.) (XIII)", en Gaceta de Tenerife. Santa Cruz de Tenerife, 3 de mayo de 1936. p. 3.

"Los condes de La Gomera (marqueses de Adeje, señores de la isla del Hierro, etc.) (XIV)", en Gaceta de Tenerife. Santa Cruz de Tenerife, 5 de mayo de 1936. p. 3.

"Los condes de La Gomera (marqueses de Adeje, señores de la isla del Hierro, etc.) (XV)", en Gaceta de Tenerife. Santa Cruz de Tenerife, 7 de mayo de 1936. p. 3.

"Los condes de La Gomera (marqueses de Adeje, señores de la isla del Hierro, etc.) (XVI)", en Gaceta de Tenerife. Santa Cruz de Tenerife, 8 de mayo de 1936. p. 3.

"Los condes de La Gomera (marqueses de Adeje, señores de la isla del Hierro, etc.) (XVII)", en Gaceta de Tenerife. Santa Cruz de Tenerife, 13 de mayo de 1936. p. 3. 
"Los condes de La Gomera (marqueses de Adeje, señores de la isla del Hierro, etc.) (XVIII)", en Gaceta de Tenerife. Santa Cruz de Tenerife, 15 de mayo de 1936. p. 3.

"Los condes de La Gomera (marqueses de Adeje, señores de la isla del Hierro, etc.) (XIX)", en Gaceta de Tenerife. Santa Cruz de Tenerife, 16 de mayo de 1936. p. 3.

"Los condes de La Gomera (marqueses de Adeje, señores de la isla del Hierro, etc.) (XX)", en Gaceta de Tenerife. Santa Cruz de Tenerife, 17 de mayo de 1936. p. 3.

"Los condes de La Gomera (marqueses de Adeje, señores de la isla del Hierro, etc.) (XXI)", en Gaceta de Tenerife. Santa Cruz de Tenerife, 20 de mayo de 1936. p. 5.

"Los condes de La Gomera (marqueses de Adeje, señores de la isla del Hierro, etc.) (XXII)", en Gaceta de Tenerife. Santa Cruz de Tenerife, 21 de mayo de 1936. p. 3.

"Los condes de La Gomera (marqueses de Adeje, señores de la isla del Hierro, etc.) (XXIII)", en Gaceta de Tenerife. Santa Cruz de Tenerife, 22 de mayo de 1936. p. 3.

"Los condes de La Gomera (marqueses de Adeje, señores de la isla del Hierro, etc.) (XXIV)", en Gaceta de Tenerife. Santa Cruz de Tenerife, 23 de mayo de 1936. p. 3.

"Los condes de La Gomera (marqueses de Adeje, señores de la isla del Hierro, etc.) (XXV)", en Gaceta de Tenerife. Santa Cruz de Tenerife, 24 de mayo de 1936. p. 3.

"Los condes de La Gomera (marqueses de Adeje, señores de la isla del Hierro, etc.) (XXVI)", en Gaceta de Tenerife. Santa Cruz de Tenerife, 27 de mayo de 1936. p. 3.

"Los condes de La Gomera (marqueses de Adeje, señores de la isla del Hierro, etc.) (XXVII)", en Gaceta de Tenerife. Santa Cruz de Tenerife, 28 de mayo de 1936. p. 3.

"Los condes de La Gomera (marqueses de Adeje, señores de la isla del Hierro, etc.) (XXVIII)", en Gaceta de Tenerife. Santa Cruz de Tenerife, 31 de mayo de 1936. p. 3.

"Los condes de La Gomera (marqueses de Adeje, señores de la isla del Hierro, etc.) (XXX)", en Gaceta de Tenerife. Santa Cruz de Tenerife, 4 de junio de 1936. p. 3.

"Los condes de La Gomera (marqueses de Adeje, señores de la isla del Hierro, etc.) (XXXI)", en Gaceta de Tenerife. Santa Cruz de Tenerife, 6 de junio de 
1936. p. 3.

"Los condes de La Gomera (marqueses de Adeje, señores de la isla del Hierro, etc.) (XXXII)", en Gaceta de Tenerife. Santa Cruz de Tenerife, 7 de junio de 1936. p. 3.

"Los condes de La Gomera (marqueses de Adeje, señores de la isla del Hierro, etc.) (XXXIII)", en Gaceta de Tenerife. Santa Cruz de Tenerife, 10 de junio de 1936. p. 3.

"Los condes de La Gomera (marqueses de Adeje, señores de la isla del Hierro, etc.) (XXXIV)", en Gaceta de Tenerife. Santa Cruz de Tenerife, 11 de junio de 1936. p. 3.

"Los condes de La Gomera (marqueses de Adeje, señores de la isla del Hierro, etc.) (XXXV)", en Gaceta de Tenerife. Santa Cruz de Tenerife, 14 de junio de 1936. p. 3.

"Los condes de La Gomera (marqueses de Adeje, señores de la isla del Hierro, etc.) (XXXVI)", en Gaceta de Tenerife. Santa Cruz de Tenerife, 18 de junio de 1936. p. 3.

"Los condes de La Gomera (marqueses de Adeje, señores de la isla del Hierro, etc.) (XXXVII)", en Gaceta de Tenerife. Santa Cruz de Tenerife, 24 de junio de 1936. p. 3.

"Los condes de La Gomera (marqueses de Adeje, señores de la isla del Hierro, etc.) (XXXVIII)", en Gaceta de Tenerife. Santa Cruz de Tenerife, 30 de junio de 1936. p. 3.

"Los condes de La Gomera (marqueses de Adeje, señores de la isla del Hierro, etc.) (XXXIX)", en Gaceta de Tenerife. Santa Cruz de Tenerife, 4 de julio de 1936. p. 3.

"Los condes de La Gomera (marqueses de Adeje, señores de la isla del Hierro, etc.) (XL)", en Gaceta de Tenerife. Santa Cruz de Tenerife, 8 de julio de 1936. p. 3.

"Los condes de La Gomera (marqueses de Adeje, señores de la isla del Hierro, etc.) (XLI)", en Gaceta de Tenerife. Santa Cruz de Tenerife, 9 de julio de 1936. p. 3.

"Los condes de La Gomera (marqueses de Adeje, señores de la isla del Hierro, etc.) (XLIII)", en Gaceta de Tenerife. Santa Cruz de Tenerife, 25 de julio de 1936. p. 3.

"Desorientación ciudadana", en Gaceta de Tenerife. Santa Cruz de Tenerife, 18 de mayo de 1937. pp. 1-2. 
"Las Hermandades del Santísimo", en Gaceta de Tenerife. Santa Cruz de Tenerife, 27 de mayo de 1937. p. 3.

"Famosas fiestas del Corpus", en La Prensa. Santa Cruz de Tenerife, 27 de mayo de 1937. pp. 1-2.

"Impresiones artístico-históricas. Las pinturas murales del municipio (I)", en La Prensa. Santa Cruz de Tenerife, 1 de julio de 1937. p. 2.

"Impresiones artístico-históricas. Las pinturas murales del municipio (y II)", en La Prensa. Santa Cruz de Tenerife, 6 de julio de 1937. p. 2.

"Una fecha histórica, 25 de Julio. 1797-1937. El hecho de armas que dio renombre a Santa Cruz de Tenerife", en Gaceta de Tenerife. Santa Cruz de Tenerife, 25 de julio de 1937. p. 4.

"La fiesta del pendón", en La Prensa. Santa Cruz de Tenerife, 27 de julio de 1937. p. 1.

"Recuerdos históricos de la fiesta y Virgen de Candelaria», en La Prensa. Santa Cruz de Tenerife, 14 de agosto de 1937. p. 1.

"Los árboles históricos de Canarias. "El Garoé", el famoso árbol de la isla de El Hierro", en La Prensa. Santa Cruz de Tenerife, 15 de agosto de 1937. p. 3.

"De libros nuevos. Fray José de Sosa», en El Día. Santa Cruz de Tenerife, 2 de agosto de 1939. p. 2.

"Semi-historia de fundaciones jesuitas en Canarias (I)", en El Día. Santa Cruz de Tenerife, 23 de agosto de 1939. p. 2.

"Semi-historia de fundaciones jesuitas en Canarias (IV)", en El Día. Santa Cruz de Tenerife, 7 de septiembre de 1939. p. 2.

"Semi-historia de fundaciones jesuitas en Canarias (VI)", en El Día. Santa Cruz de Tenerife, 16 de septiembre de 1939. p. 2.

"Semi-historia de fundaciones jesuitas en Canarias (y VII)", en El Día. Santa Cruz de Tenerife, 20 de septiembre de 1939. p. 2.

"Sucesos del siglo XVIII. Incendio del palacio de los Celadas", en El Día. Santa Cruz de Tenerife, 3 de diciembre de 1939. p. 1.

"La fiesta de la Inmaculada", en El Día. Santa Cruz de Tenerife, 8 de diciembre de 1939. p. 1.

"El Cristo de Tacoronte», en La Tarde. Santa Cruz de Tenerife, 23 de septiembre de 1940. p. 1. 
"E1 puente Zurita (I)", en La Tarde. Santa Cruz de Tenerife, 25 de noviembre de 1940. p. 2.

"El puente Zurita (y II)", en La Tarde. Santa Cruz de Tenerife, 9 de diciembre de 1940. p. 2.

"Los Adelantados de Canarias" y Rodríguez Moure, Póstumo homenaje al presbitero don José Rodríguez Moure, cronista de La Laguna. La Laguna: RSEAPT. pp. $74-81$.

"La casa canaria de Tenerife», en Mirador. Santa Cruz de Tenerife. n ${ }^{\circ} 13$.

"Breves consideraciones históricas sobre los Adelantados de Canarias", en Los Adelantados de Canarias, de José Rodriguez Moure. La Laguna: RSEAPT. pp. VII-XXVI.

"Los condes de La Gomera (I)", en Revista de Historia. La Laguna: Universidad. VII(55), pp. 269-280.

"Los condes de La Gomera (II)", en Revista de Historia. La Laguna: Universidad. VII(56), pp. 330-346.

"Los antiguos alcaldes de Santa Cruz (I)", en La Tarde. Santa Cruz de Tenerife, 16 de enero de 1941. p. 3.

"Los jesuitas en Tenerife», en Criterio. Santa Cruz de Tenerife, 19 de enero de 1941. pp. 10-11.

"Los antiguos alcaldes de Santa Cruz (II)", en La Tarde. Santa Cruz de Tenerife, 3 de febrero de 1941. p. 1.

"Los antiguos alcaldes de Santa Cruz (III)", en La Tarde. Santa Cruz de Tenerife, 10 de febrero de 1941. p. 3.

"Los castellanos de San Cristóbal (I)", en La Tarde. Santa Cruz de Tenerife, 27 de marzo de 1941. p. 2.

"Los castellanos de San Cristóbal (II)", en La Tarde. Santa Cruz de Tenerife, 4 de abril de 1941. p. 2.

"Los castellanos de San Cristóbal (y III)", La Tarde. Santa Cruz de Tenerife, 14 de abril de 1941. p. 2.

"Los condes de La Gomera (ampliaciones y rectificaciones) (I)", en Revista de Historia. La Laguna: Universidad. VIII(57), pp. 55-63.

"Los condes de La Gomera (ampliaciones y rectificaciones) (II)", en Revista de Historia. La Laguna: Universidad. XV(58), pp. 90-98. 
"Los condes de La Gomera (ampliaciones y rectificaciones) (III)", en Revista de Historia. La Laguna: Universidad. VIII(59), pp. 156-173.

"La casa de la familia de La Torre", en La Tarde. Santa Cruz de Tenerife, 17 de abril de 1942. p. 3.

"La casa de los Calderines y Abreus", en La Tarde. Santa Cruz de Tenerife, 28 de mayo de 1942. p. 3.

"Del pasado santacrucero. La Calle Grande", en La Tarde. Santa Cruz de Tenerife, 13 de agosto de 1942. p. 3.

"La casa-palacio de Mejorada", en La Tarde. Santa Cruz de Tenerife, 28 de septiembre de 1942. p. 3.

"Los condes de La Gomera (documentos y notas históricas) (IV)", en Revista de Historia. La Laguna: Universidad. IX(62), pp. 149-153.

"Los condes de La Gomera (documentos y notas históricas) (V)", en Revista de Historia. La Laguna: Universidad. IX(63), pp. 222-235.

"Los condes de La Gomera (documentos y notas históricas) (y VI)", en Revista de Historia. La Laguna: Universidad. IX(64), pp. 300-315.

"La ermita de Regla y la epidemia de 1810", en La Tarde. Santa Cruz de Tenerife, 16 de marzo de 1943. p. 3.

"En recuerdo de un amigo. El escritor Arocha y Guillama", en La Tarde. Santa Cruz de Tenerife, 7 de mayo de 1943. p. 3.

"Del pasado santacrucero. Concesión de datas para solares (I)", en La Tarde. Santa Cruz de Tenerife, 6 de julio de 1943. p. 3.

"Del pasado santacrucero. Concesión de datas para solares (y II)", en La Tarde. Santa Cruz de Tenerife, 8 de julio de 1943. p. 3.

"La moneda provincial [I]", en La Tarde. Santa Cruz de Tenerife, 11 de febrero de 1944. p. 2.

"La moneda provincial [II]", en La Tarde. Santa Cruz de Tenerife, 14 de febrero de 1944. p. 3.

"La moneda provincial [III]", en La Tarde. Santa Cruz de Tenerife, 16 de febrero de 1944. p. 3.

"La moneda provincial [IV]", en La Tarde. Santa Cruz de Tenerife, 17 de febrero de 1944. p. 3.

"La moneda provincial [V]", en La Tarde. Santa Cruz de Tenerife, 1 de marzo 
de 1944. p. 3.

"La moneda provincial [VI]", en La Tarde. Santa Cruz de Tenerife, 3 de marzo de 1944. p. 3.

"La moneda provincial [VII]", en La Tarde. Santa Cruz de Tenerife, 9 de marzo de 1944. p. 3.

"La moneda provincial [y VIII]", en La Tarde. Santa Cruz de Tenerife, 13 de marzo de 1944. p. 3.

"El escultor Marcelo Gómez (I)", en La Tarde. Santa Cruz de Tenerife, 19 de abril de 1944. p. 2.

"El escultor Marcelo Gómez (y II)", en La Tarde. Santa Cruz de Tenerife, 22 de abril de 1944. p. 3.

"El compositor Eugenio Domínguez (I)", en La Tarde. Santa Cruz de Tenerife, 30 de junio de 1944. p. 2.

"El compositor Eugenio Domínguez (y II)", en La Tarde. Santa Cruz de Tenerife, 13 de julio de 1944. p. 3

"Tradiciones icodenses. La ermita del Tránsito", en La Tarde. Santa Cruz de Tenerife, 15 de agosto de 1944. p. 3.

"Festividad del Socorro en Tegueste», en El Día. Santa Cruz de Tenerife, 24 de septiembre de 1944, p. 3.

"Vilaflor y su parroquia (I)", en El Día. Santa Cruz de Tenerife, 26 de octubre de 1944 , p. 3.

"El sargento mayor de Tenerife», en La Tarde. Santa Cruz de Tenerife, 26 de octubre de 1944. p. 3.

"Vilaflor y su parroquia (I)", en El Día. Santa Cruz de Tenerife, 26 de octubre de 1944.

"Vilaflor y su parroquia (II)", en El Día. Santa Cruz de Tenerife, 27 de octubre de 1944 , p. 3.

"Vilaflor y su parroquia (III)", en El Día. Santa Cruz de Tenerife, 1 de noviembre de 1944 , p. 3.

"Vilaflor y su parroquia (y IV)", en El Día. Santa Cruz de Tenerife, 5 de noviembre de 1944, p. 3.

"Los coroneles de milicias (I)", en La Tarde. Santa Cruz de Tenerife, 21 de noviembre de 1944. p. 3. 
"Los coroneles de milicias (y II)", en La Tarde. Santa Cruz de Tenerife, de noviembre de 1944. p. 3.

"Algunas modalidades históricas de la nobleza de Canarias", en Estatuto Nobiliario. Madrid: C.S.I.C. pp. 441-452.

"Del pasado tinerfeño. El historiador Núñez de la Peña y su tiempo (I)", en Revista de Historia. La Laguna: Universidad. XI(69), pp. 3-25.

"Del pasado tinerfeño. El historiador Núñez de la Peña y su tiempo (II)", en Revista de Historia. La Laguna: Universidad. XI(70), pp. 210-222.

"Del pasado tinerfeño. El historiador Núñez de la Peña y su tiempo (III)", en Revista de Historia. La Laguna: Universidad. XI(71), pp. 287-298.

"Del pasado tinerfeño. El historiador Núñez de la Peña y su tiempo (IV)", en Revista de Historia. La Laguna: Universidad. XI(72), pp. 462-472.

"Del pasado tinerfeño. El historiador Núñez de la Peña y su tiempo (y V)", en Revista de Historia. La Laguna: Universidad. XII(73), pp. 26-34.

"Santa María de La Palma", Diario de Avisos. Extraordinario Bajada de la Virgen. Santa Cruz de La Palma.

"El alcalde-castellano del Puerto de la Cruz", en La Tarde. Santa Cruz de Tenerife, 2 de enero de 1945. p. 3.

"Los capitanes de milicias de Canarias (I)", en El Día. Santa Cruz de Tenerife, 3 de enero de 1945, p. 3.

"Los capitanes de milicias de Canarias (y II)", en El Día. Santa Cruz de Tenerife, 4 de enero de 1945 , p. 3.

"El pintor Quintana y su familia", en El Día. Santa Cruz de Tenerife, 16 de enero de 1945, p. 3.

"Tradiciones laguneras. El hospital de San Sebastián", en La Tarde. Santa Cruz de Tenerife, 20 de enero de 1945. p. 3.

"Tradiciones laguneras. La iglesia de San Miguel de las Victorias", en La Tarde. Santa Cruz de Tenerife, 2 de marzo de 1945. p. 3.

"Tradiciones religiosas laguneras. La Semana Santa y sus cofradias", en La Tarde. Santa Cruz de Tenerife, 28 de marzo de 1945. p. 4.

"La parroquia matriz de La Gomera", en La Tarde. Santa Cruz de Tenerife, 15 de mayo de 1945. p. 3. 
"Triptico de tradiciones laguneras", en La Tarde. Santa Cruz de Tenerife, 17 de julio de 1945. p. 3.

[Reseña de la obra El Puerto de la Cruz y los Iriarte, de Diego M. Guigou y Costa], en El Día. Santa Cruz de Tenerife, 11 de agosto de 1945.

"Viejas estampas sobre la Candelaria (tríptico)", en La Tarde. Santa Cruz de Tenerife, 15 de agosto de 1945. p. 3.

"Santa Cruz de Tenerife a través de su historia (I)", en La Tarde. Santa Cruz de Tenerife, 25 de agosto de 1945. p. 3.

"Santa Cruz de Tenerife a través de su historia (II)", en La Tarde. Santa Cruz de Tenerife, 5 de septiembre de 1945. p. 3.

"Santa Cruz de Tenerife a través de su historia (III)", en La Tarde. Santa Cruz de Tenerife, 19 de septiembre de 1945. p. 3.

"Santa Cruz de Tenerife a través de su historia (IV)", en La Tarde. Santa Cruz de Tenerife, 26 de septiembre de 1945. p. 3.

"Santa Cruz de Tenerife a través de su historia (y V)", en La Tarde. Santa Cruz de Tenerife, 12 de octubre de 1945. p. 3.

"Santa Cruz, a través del XVIII (I)", en La Tarde. Santa Cruz de Tenerife, 29 de noviembre de 1945. p. 3.

"Santa Cruz, a través del XVIII (II)", en La Tarde. Santa Cruz de Tenerife, 30 de noviembre de 1945. p. 2.

"Efemérides herreñas. Cuarto centenario mariano", en El Día. Santa Cruz de Tenerife, 27 de diciembre de 1945, p. 3.

"La Junta Gubernativa de Fuerteventura", en El Museo Canario. Las Palmas de Gran Canaria. VI(15), pp. 15-16.

"La Junta Gubernativa de Lanzarote», en El Museo Canario. Las Palmas de Gran Canaria. VII(18), pp. 19-34.

"Santa Cruz, a través del XVIII (III)", en La Tarde. Santa Cruz de Tenerife, 2 de enero de 1946. p. 3.

"Santa Cruz, a través del XVIII (IV)", en La Tarde. Santa Cruz de Tenerife, 12 de enero de 1946. p. 3.

"Santa Cruz, a través del XVIII (V)", en La Tarde. Santa Cruz de Tenerife, 2 de marzo de 1946. p. 3.

"Los servicios postales de antaño", en La Tarde. Santa Cruz de Tenerife, 3 de 
abril de 1947. p. 4.

"El nuevo obispo de Tenerife», en El Día. Santa Cruz de Tenerife, 1 de mayo de 1947. p. 3.

"E1 nuevo escudo episcopal», en El Día. Santa Cruz de Tenerife, 24 de julio de 1947.

"Los servicios postales de antaño", en La Tarde. Santa Cruz de Tenerife, 5 de agosto de 1947. p. 3.

"Los montes de la isla de El Hierro", en La Tarde. Santa Cruz de Tenerife, 19 de septiembre de 1947. p. 3.

"La feudal "Torre del Conde", en La Gomera", en La Tarde. Santa Cruz de Tenerife, 4 de noviembre de 1947. p. 3.

"Antecedentes históricos. El venerable Padre Anchieta y su familia", en La Tarde. Santa Cruz de Tenerife, 26 de junio de 1948. p. 1.

"Los comienzos en Tenerife de la cochinilla", en El Día. Santa Cruz de Tenerife, 1 de octubre de 1948, p. 3.

"El centro docente más antiguo de la provincia», en El Día. Santa Cruz de Tenerife, 26 de octubre de 1948, pp. 1 y 3.

"Los hebreos en Canarias", en El Día. Santa Cruz de Tenerife, 26 de noviembre de 1948. p. 3.

"Las primeras imprentas de Tenerife», en La Tarde. Santa Cruz de Tenerife, 9 de enero de 1949. p. 3.

"Monumentos del Jueves Santo", en El Día. Santa Cruz de Tenerife, 13 de abril de 1949. p. 4.

"Sumaria histórica orgánica de las Milicias de Canarias. Parte I", en El Museo Canario. Las Palmas de Gran Canaria. (37/40), pp. 99-208.

"Sumaria histórica orgánica de las Milicias de Canarias. Parte II", en El Museo Canario. Las Palmas de Gran Canaria. (53/56), pp. 1-36.

"Visita a la parroquia de San Sebastián [de La Gomera]", en La Tarde. Santa Cruz de Tenerife, 14 de febrero de 1951. p. 3.

"El Juzgado de Indias en La Palma», en El Día. Santa Cruz de Tenerife, 3 de abril de 1951. p. 3.

"Episodios de nuestro antiguo comercio de Indias. Corruptelas a la sombra", en La Tarde. Santa Cruz de Tenerife, 24 de marzo de 1952. p. 3. 
"Peñas y Zamoras", en La Tarde. Santa Cruz de Tenerife, 14 de noviembre de 1953. p. 4.

"Los antiguos regidores de Canarias", en Estudios genealógicos, heráldicos y nobiliarios. Madrid. 5, pp. 293-304.

"Repeliendo desconsiderados ataques", en Revista de Historia. La Laguna: Universidad. XX(105/108), pp. 90-93.

"De historia tinerfeña. La reposición de un regidor", en La Tarde. Santa Cruz de Tenerife, 7 de enero de 1954. p. 4.

"El Real Hospital de Nuestra Señora de los Dolores», en La Tarde. Santa Cruz de Tenerife, 28 de enero de 1954. p. 7.

"Los Anchieta en Tenerife», en La Tarde. Santa Cruz de Tenerife, 22 de marzo de 1954. p. 4.

"El alguacilazgo mayor de la isla de La Palma", en La Tarde. Santa Cruz de Tenerife, 3 de mayo de 1954. p. 3.

"Ojeada general sobre la antigua vida militar gomera", en La Tarde. Santa Cruz de Tenerife, 7 de enero de 1955. p. 4.

"La isla de El Hierro (IV)", en La Tarde. Santa Cruz de Tenerife, 23 de junio de 1955. p. 7.

"Los antiguos gremios (I)", en La Tarde. Santa Cruz de Tenerife, 23 de diciembre de 1955. p. 3.

"Los antiguos gremios (y II)", en La Tarde. Santa Cruz de Tenerife, 26 de diciembre de 1955. p. 7.

"A propósito de los condes de La Gomera. ¿Fue antaño regular la sucesión de este título?", en Hidalguía. Madrid. n 14. pp. 40-58.

"Misceláneas históricas palmeras. Asuntos gremiales y de castrametación", en La Tarde. Santa Cruz de Tenerife, 19 de marzo de 1956. p. 4.

"Sucinta historia sobre la religión católica en Canarias", Historia de la religión en Canarias. Santa Cruz de Tenerife: Ed. Cervantes. pp. 3-286.

"La villa de La Orotava y sus antiguos privilegios", en El Día. Santa Cruz de Tenerife, 22 de abril de 1957.

"El antiguo partido de Daute», en El Día. Santa Cruz de Tenerife, 1 de junio de 1957.

"Los antiguos alcaldes pedáneos", en El Día. Santa Cruz de Tenerife, 12 de 
junio de 1957.

"De un manual de historia general de Canarias próximo a publicarse", en $\mathrm{Fa}$ lange. Las Palmas de Gran Canaria, 2 de noviembre de 1957. p. 3.

"Evocaciones históricas de 1558", en La Tarde. Santa Cruz de Tenerife, 12 de febrero de 1958. p. 3.

"Evocaciones históricas de 1658", en La Tarde. Santa Cruz de Tenerife, 18 de marzo de 1958. p. 3.

"La Santa Cruz de mayo", en El Día. Santa Cruz de Tenerife, 3 de mayo de 1958. p. 5.

"Peculiaridades de los Cabildos canarios: cuadro de sus autoridades (I)", en La Tarde. Santa Cruz de Tenerife, 10 de noviembre de 1958. p. 3 .

"Peculiaridades de los Cabildos canarios: cuadro de sus autoridades (y II)", en La Tarde. Santa Cruz de Tenerife, 13 de noviembre de 1958. p. 3.

"Consideraciones históricas sobre la Real Sociedad Económica de Amigos del País de Tenerife", en Sesión celebrada con motivo de la inauguración oficial de sus nuevos locales: (San Agustín, 23), el dia 21 de noviembre de 1959. La Laguna: RSEAPT. pp. 25-40.

"Recuerdos del pasado gomero. Su desaparecida Económica", en La Tarde. Santa Cruz de Tenerife, 6 de febrero de 1959. p. 4.

"El conquistador Gonzalo del Castillo", en La Tarde. Santa Cruz de Tenerife, 6 de abril de 1959. p. 3.

"La enseñanza en Tenerife (y II)", en La Tarde. Santa Cruz de Tenerife, 30 de abril de 1959.

"A través de la historia. Cívicas conmemoraciones santacruceras", en El Día. Santa Cruz de Tenerife, 28 de mayo de 1959. p. 25.

"Pendones y banderas antiguos", en La Tarde. Santa Cruz de Tenerife, 6 de agosto de 1959. p. 3.

"La torre de San Miguel de Garachico (I)", en El Día. Santa Cruz de Tenerife, 6 de abril de 1960. p. 3.

"La torre de San Miguel de Garachico (y II)", en El Día. Santa Cruz de Tenerife, 17 de abril de 1960. p. 9.

"Evocaciones históricas isleñas. Efemérides del año 1560)", en El Día. Santa Cruz de Tenerife, 23 de julio de 1960. 


\title{
Selección de aRtículos de Dacio Victoriano DaRias y PadRón
}

\author{
EPISOdIOS DE NUESTRO ANTIGUO COMERCIO DE INDIAS. CORRUPTELAS A SU SOMBRA
}

[La Tarde, Santa Cruz de Tenerife, 24 de marzo de 1952, p. 3]

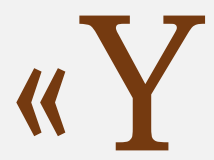

a hemos manifestado en otra ocasión y lugar que desde nuestra antigua Revista de Historia, hoy órgano cientifico publicitario de la Facultad de Filosofia y Letras, revista a la que desde su fundación en 1926 hasta fines de 1929, en que traspasamos su propiedad a uno de sus tres más asiduos colaboradores, que luego como signo sintomático de su gratitud, quiso convertirse en uno de los personajes de la fábula titulada "Graculus supervus, et Pavo" — ¿la recuerda el lector?-, publicación a la que entonces dedicamos por entero nuestros afanes y pérdidas de tiempo, se está publicando, bien que un poco festivamente, una monografia dedicada a nuestro antiguo comercio de Indias, a la que remitimos, con ciertas reservas nuestras a los lectores de esta crónica.

El empeño del citado autor desde luego lo reputamos laudable en cuanto a su intento heurístico, por lo menos, si prescindimos como queremos prescindir ahora, de sus posibles deficiencias, algo de pesadez y cierta falta de sistematización, circunstancias que disculpamos en cierto modo, ya sea por su falta de preparación en cuanto a su carencia de base técnica comercial y de un conocimiento siquiera elemental, en el campo de la historia, tanto de nuestra economía clásica como de la mundial, que tuvo sus repercusiones en las islas. Habría que conocer, además, algo de autores tales como nuestro Colmetro, cuya lectura, sin embargo, no debe aceptarse sin algunas prevenciones, hasta autores de nuestros dias especializados en la materia, publicistas que conocieron y conocen a fondo la materia; y en el detalle, épocas donde ocurrieron acontecimientos del volumen de la Reforma, descubrimientos y otras invenciones, que originaron, indudablemente, el despliegue del capital, entonces por lo general, concentrado en pocas manos, junto con aquella ingente inundación de metales preciosos, cuyo fenómeno económico causó entonces a nuestra nación, la descubridora de nuevas tierras y la proveedora de aquel acervo crematístico, su empobrecimiento y ruina.

Aquí en Canarias, el comercio entonces con América dio origen -la historia se repite a veces - a grandes fraudes y abusos de todo orden debido, principalmente, a la intervención de extranjeros que en todos tiempos buscaron y lograron muchas veces, rápidas fortunas en nuestras islas. Nos traían ropas y otros artículos de contrabando, que luego vendian y trocaban por vinos, grana, tabaco, añil y otros artículos de fácil adquisición en el Nuevo Mundo. 
También zarpaban muchos navios de nuestros puertos con rumbo a Indias, con cargamento de aquellos artículos de procedencia extranjera, buques que, en sus viajes de retorno, traian a bordo "grandes sumas de oro, plata y cosas preciosas, para hacer nuevos empleos con que por este camino se llenan de ropa las Indias y cuando van a ellas las flotas no tienen salida los géneros que llevan".

Estos y otros abusos semejantes pusieron más de una vez en peligro de zozobrar nuestra permisión de Indias, ya que la Corona en cédula de 19 de abril de 1649, llegó a suprimir en las islas mayores (Tenerife, Gran Canaria y La Palma) la concesión que entonces disfrutaban de 700 toneladas de frutos isleños a Tierra Firme e islas de Barlovento, si bien luego ante una representación de las islas, se prorrogó el privilegio por unos seis años, que antes se habia otorgado por Real Cédula de 27 de enero de 1632. Por ejemplo, a La Palma se le habian concedido dentro del cupo unas 200 toneladas para los indicados puntos con exclusión de Nueva España o México, Campeche, Honduras y La Habana.

En vano el Consejo de Indias trató de corregir abusos. Estos prosiguieron y una nueva disposición de la Corona, su fecha 6 de enero de 1652, ordenó al entonces juez de Indias, el bachiller Cristóbal Soberanis, que en la permisión correspondiente a la isla de La Palma, vivero entonces de muchos mercaderes extranjeros, se guardara invariablemente lo dispuesto en las ordenanzas de la Casa de Contratación y la demás legislación mercantil que regulaba la materia. Y que se pusiera especial cuidado en que no llevasen a ultramar mercancías prohibidas, ni mayor cantidad de la previamente permitida, y que los viajes de retorno se rindieran en la misma Casa de la Contratación y que nunca derrotaran en otros parajes. Esta y otras disposiciones que contiene el cedulario de Indias no impidieron la radicación de abusos y los contrabandos, que seguirian alimentando, hasta el término de tal comercio isleño, a los "estraperlistas" de aquella época.

Ejercía por entonces en La Palma, por subdelegación del bachiller Soberanis, el oficio de juez de Indias de aquella y de la isla de El Hierro, el genovés naturalizado en las Islas, Juan Ángel Poggio, que se titulaba maestre de campo, a quien había dado posesión del cargo en 9 de diciembre de 1651 el oidor de la Real Audiencia, don Diego Cejudo e Hidalgo, famoso togado en Canaria. Antes había desempeñado ese cargo en La Palma su teniente de corregidor, el licenciado don Cristóbal Landin Machado. Era allí escribano de tal juzgado el capitán don Matías de Escobar Pereira, regidor perpetuo de La Palma. Esto indicaba lo lucrativo de aquel oficio fedatario.

Es de observar, sin embargo, que entonces había hecho oposición al nombramiento de Poggio el Cabildo de La Palma, cuyo organismo municipal, ignoramos en virtud de qué atribuciones, que en manera alguna le competían, había nombrado juez subdelegado al propio corregidor de Tenerife y La Palma, don Antonio Girón. Pero el agraviado Poggio recurrió a la Real Audiencia y esta, en provisión de 20 de noviembre de 1651 y sobrecarta del día 22, mandó dar posesión al reclamante. 
Sería curioso, por último, que alguien con tiempo y preparación suficientes en cuanto a instrucción, fidelidad, imparcialidad, libertad contraria a la populacheria, discernimiento y moralidad, dotes todas de un auténtico historiador, extractara de los maltrechos legajos del antiguo archivo de la Audiencia de Canaria, donde nosotros mismos hemos realizado rápidas investigaciones, algo de la historia judicial, tanto civil como criminal, acerca de nuestras islas. ¡Cuántas sorpresas nos proporcionaría y cuántas reputaciones históricas consagradas quedarian hechas polvo! No es lo mismo escribir, desgraciadamente, como historiadores que como genealogistas, donde esta rama de la Historia a menudo se desacredita por algunos, admitiendo sin escrúpulos burdas invenciones y ridículos mitos. $\|$ 


\section{El Centro docente más antiguo de Canarias}

[El Día, Santa Cruz de Tenerife, 26 de octubre de 1948, pp. 1 y 3]

\section{«F}

ueron los hijos de Canarias, desde los lejos tiempos de la conquista, por la misma condición insular y geográfica del Archipiélago, muy aficionados a buscar sus expansiones comerciales por la ruta marítima, entonces asaz peligrosa y arriesgada, sobre todo en el penoso rumbo de Indias, aunque compensadas, a veces, con la adquisición, derivada de tal tráfico, de largos caudales. De ahí que a partir del siglo XVI hasta tiempos bien cercanos, se dedicaron los isleños a la navegación mercante, bien en buques propios o ajenos, ya indistintamente como capitanes o como maestres a bordo de los mismos navios de la Carrera.

Hemos tenido ocasión de leer en antiguos registros de Indias los apellidos corrientes entonces en tales marinos mercantes, que por la dureza de los tiempos también tenian que tener la condición de corsarios: Botino, Calimano, Castro Carriazo, Cubas, Dapelo, Eduardo, Fierro, Franco de Castilla, Garcia, González de Mesa, Madan, Mesa, Miranda, Román, Rodríguez de Molina, Sall, Saviñón, Tolosa, Bandama, Vandenheede, Viña, Wadding y otros tantos, pertenecientes desde las clases más alcurniadas, algunos llegaron a ser títulos de Castilla, hasta las de condición media.

Tales buques canarios, que se dirigian a puertos de América española, tenian que abonar antes de hacerse a la mar, entre sus muchas gabelas, 14 reales antiguos por cada tonelada de carga en favor del Real Seminario de San Telmo en Sevilla, colegio de Marinería, Pilotaje y Artillería, fundado en 1681 por Carlos II, y puesto bajo la administración de la Universidad de Mareantes, corporación erigida en 1569 e integrada por pilotos examinados y señores de naos, en el barrio de Triana, donde primitivamente construyeron un hospital e iglesia bajo la advocación de Nuestra Señora del Buen Aire, antes de levantar el suntuoso edificio, hoy seminario eclesiástico, de San Telmo.

Al ser creados en provincias, allí donde no existian los Reales Consulados Terrestres y Marítimos, se encomendó a estos organismos el tener a su cargo las Escuelas Náuticas, con la única excepción de los Colegios Castrenses de Marina, uno en San Telmo y otro en Málaga. El Consulado de Tenerife, con sede en La Laguna, no tardó en percatarse, como ya antes lo había propugnado la Económica de Tenerife, de la conveniencia de instaurar en las Islas una Escuela de Dibujo y Náutica. Y en cuanto sus recursos se lo permitieron, llevó a cabo tal resolución en junta consular de 2 de mayo de 1810, bajo la presidencia de don Cayetano Peraza y Ayala, en ausencia de su prior, el marqués de la Fuente de Las Palmas, de lo que dio fe el secretario don Lorenzo de Montemayor. Fueron designados profesores de Dibujo y Náutica, respectivamente, con el sueldo anual para cada uno de 500 pesos don Luis de la Cruz y Ríos, y el piloto, práctico en la navegación de Indias, don Ambrosio Martínez de Fuentes. Se acudió a la Sociedad Económica para la redacción del reglamento del nuevo centro docente, que nombró para esto - sesión del 5 de mayo, presidida por el conde del Valle Salazar- a sus socios don Bernardo de Mesa 
y don Domingo Saviñón, con la cooperación de otros colegas, y se abrió el curso en los bajos de la casa del Consulado el 29 de mayo del propio día de la festividad del rey cautivo en Francia. Por cierto, que en tal sesión de la Económica ya se habló de reanimar la Real Sociedad, "que tanto concepto había adquirido en nuestra provincia y que iba ya corriendo la misma suerte que otros interesantes establecimientos", y aún abrigó el proyecto (uno de sus cantos de cisne por entonces, aunque a ratos ha revivido de sus propias cenizas como el __ de la fábula) de la creación de una cátedra de Agricultura.

Al desaparecer el Consulado, que fue sustituido por la Junta de Comercio, con residencia en la capital de la provincia, esta nueva corporación continuó sosteniendo la Náutica, que hizo trasladar a Santa Cruz como puerto de mar, con sin algunos forcejeos que resultaron inútiles a la postre por parte de los laguneros, desde que dejaron de contar con la influencia de su hijo preclaro, el arzobispo Bencomo. Pero al quedar reducidas en fines de 1847 las funciones de la Junta de Comercio y ser centralizados sus fondos en el Ministerio de Comercio, Instrucción Pública y Obras Públicas, la situación de la Náutica quedó en condiciones bastante precarias. Gracias a que la Diputación Provincial con su ayuda evitó el cierre de la Escuela, que contó entre su profesorado antiguo con prestigiosos maestros como los Maffiottes, Marin del Corral, Pereira, don Agustín __ y otros, quienes produjeron con sus sabias enseñanzas en todo tiempo discípulos que tanto honraron a nuestra marina mercante canaria.

Hoy puede nuestra Náutica gloriarse de ser el centro docente más antiguo de la provincia y de continuar, quizá con ventaja, las instructivas y técnicas tradiciones de la Casa, así como el Seminario Diocesano de Canaria puede ufanarse de ser el decano de los establecimientos de enseñanza de Canarias. Fundado en 1777 por el obispo Fr. Juan de Cervera, sus estatutos y constituciones fueron aprobados por el Consejo de Castilla en 22 de noviembre de 1780. Estuvo agregada mucho tiempo a la Universidad Literaria de Sevilla y de sus aulas han salido muchos hijos que han honrado a Canarias por su patriotismo y talentos. $\gg$ 


\section{LOS HEBREOS EN CANARIAS}

[El Día, Santa Cruz de Tenerife, 26 de noviembre de 1948, p. 3]

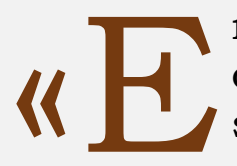

ntre el pequeño mundillo que todavía pueda dar alguna importancia a estas cuestiones de racismo, no por lo que hoy significan en sí sino por lo que entrañaban respecto de la mayor o menor pureza de las alcurnias, ha causado cierta expectativa la obra en publicación del docto y joven catedrático señor Rumeu de Armas, en la que, al abordar el tema de la piratería mundial del siglo XVI para acá, la relaciona con nuestra historia regional y en la que también, de paso, parece pone de relieve el origen judio a sus contactos posibles, de algunas familias, que luego fueron reputadas en el país como patricias, por los destacados servicios que en el terruño prestaron durante su época. Se trata, empero, de un fenómeno social no privativo de Canarias y aún hoy día muchos miembros de la aristocracia inglesa traen próximo origen semítico, sin que por ello tiemblen las esferas. Igual ocurre en la católica Austria y en la protestante Alemania.

Hoy esta cuestión étnica en su aspecto moral y social dista de ser juzgada con el estrecho criterio de antaño, basado en preocupaciones religiosas populares y antievangélicas, que para nada tuvieron en cuenta las enseñanzas de San Pablo en su conocida epístola a los corintios, en la cual se declara que todos hemos sido bautizados en el mismo espíritu, para ser un solo cuerpo, sean judios o gentiles, sean esclavos o de otra condición. Esto no impidió que nuestros abuelos de entonces hicieran distinción entre cristianos "nuevos" $\mathrm{y}$ "viejos", agrupando aquellos en "confesos" o recientemente convertidos a nuestra fe, y en descendientes de tales "confesos", reparos que ahora ya no tienen razón de existir, socialmente hablando, por lo que los descendientes de tales "confesos" carecen de razonables motivos, a través de sus dieciséis o más generaciones, para rasgarse, llenos de dolor, las vestiduras, considerándolo como máculas perennes y no caducadas, que enturbian las proles más o menos aristocráticas.

A raíz de la conquista de Tenerife, muchos de esos "confesos", procedentes de Castilla y aun de Portugal, se refugiaron en nuestras islas. Generalmente variaron sus apellidos y se dedicaron a lucrativas actividades mercantiles, adquirieron riquezas y fundaron familias, muchas de las cuales, poco tiempo después, figuraron en primera línea y enlazaron con otras de cristianos viejos, "infectando", como entonces se decía, a los de pura y vieja cepa.

Cautos, como todos los de su raza sefardi, y aun aquellas otras familias que, por parentesco cognaticio, venian de aquel origen israelita, hicieron siempre los mayores esfuerzos por hacer desaparecer tales origenes "impuros", si bien otro elemento poderoso en las islas, el Santo Oficio, los investigaba con ahínco y los inscribió en uno de los dos grandes libros genealógicos que, cuidadosamente, conservaba en sus archivos secretos. Pero nunca fueron tan intangibles estos antecedentes, porque un cierto inquisidor isleño, de ilustre apellido, hizo desaparecer algunos rastros, especialmente los que afectaban a 
su propia familia, según denuncia que, después de muerto el desaprensivo sujeto, hizo a Madrid uno de sus colegas inquisitoriales.

El que esto escribe ha tenido oportunidad en Madrid de examinar, uno por uno, todos los curiosos legajos procedentes de la Inquisición de estas islas. Posee, por tanto, los elementos de juicio necesarios para respaldar estas afirmaciones y si con detalles no las ha dado, ni da a la publicidad, es porque no pretende herir sentimientos privados, bien que ya exagerados a estas alturas, de personas respetables, que todavia hoy pudieran contar con remotos antepasados que tuvieron creencias talmúdicas, por no referirnos ahora a otras razas o familias de origen berberisco o esclavo, que también aquí dejaron alguna huella.

Por último, como obligatorio colofón de estas impresiones, traemos ahora a cuento una carta que, en 1605, escribió el inquisidor de estas islas, García de Ceniceros, visitador de Tenerife, La Palma, La Gomera y El Hierro. Dice que en visita realizada a Tenerife en 1528, por su antecesor Luis de Padilla, halló en esta isla unas 195 personas de ambos sexos y en La Palma unas 44, "y en ellas declaraban ser algunos de ellos "conversos" y otros de linaje dellos, y los que, ellos o ellas, o alguno y algunos de sus ascendientes, de padres o abuelos habian sido "reconciliados" o condenados, y esto algunos con palabras afirmativas y otros en duda, y otros que lo habian oydo dezir, y con esto a tantos años y al tpo. que se dieron las dichas genealogias en las dichas yslas habia poca gente, y después acá se han augmentado mucho, ay muy pocas casas de consideración, en especial en la isla de Tenerife, que no estén maculadas con esta descendencia, y tan mudados los nombres y apellidos, que todos los tienen de los más nobles de Vizcaya y otras partes y an probado que lo son, y siendo esto así, después que los dichos ascendientes dieron sus genealogias en virtud de los dichos edictos...". Esto último alude a que hubo familias de origen entonces "impuro" que, valiéndose de testigos falsos, hicieron expedientes llamados de limpieza de sangre, por lo que fueron multados, tanto los interesados como los atestadores, por el Santo Oficio, algunos de aquellos con reincidencia. Tales eran sus porfiados empeños, naturales en sociedades basadas en privilegiados abolengos.

Habrá que recomendar a los inconformes de hoy aquello de que "dejemos nuestros padres y abuelos y, por nosotros, seamos buenos". No hay que vivir solo de vanidosos recuerdos. $\|$ 


\section{LA VIRGEN DE LOS REYES Y EL VOTO}

[El Deber, Valverde, 9 de junio de 1921, p. 1]

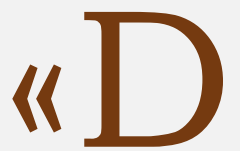

esde remotísima fecha, nuestros abuelos rindieron especial culto a Nuestra Señora de los Reyes, allá en los rincones de La Dehesa, en cuyas hondonadas y llanuras herbosas resonaría entonces el eco de baladas pastoriles acompañadas del alegre esquileo del ganado que pastaba en sus praderas, como si cantaran un himno a la excelsa Pastora. Su aparición o hallazgo casual en aquellas rinconadas debió reproducir entre los ganaderos que por alli transitaban la escena patética y bíblica de Belén. Contemplarían a la Efigia, llenos de gozo y, de hinojos ante ella, la adorarían con tierna devoción y bien pronto la candorosa imaginación de aquellos zagales inventaría leyendas poéticas, que tendrian el suave perfume de las retamas y tomillos de sus campos silentes y desérticos...

¿Qué virgen, de las que la variada gama de la fe católica venera, no las tiene? ¿Es que creemos que la religión, sentimiento esencialmente espiritual, que ha inspirado la pluma, el cincel o los pinceles de los más grandes genios de la humanidad, no tiene derecho a envolver algunos de sus episodios en el finísimo cendal del aroma de la leyenda? Si hay algo que se preste a los más bellos vuelos imaginativos es la devoción mariana, porque María, como dice Roque Barcia, cuando se despoja de su sectarismo, considerada estéticamente, es la creación más ideal y más fecunda del arte cristiano.

Respeten, pues, ante la terminante opinión de uno de los suyos, las creencias de los demás. No olvidemos, tampoco, que la Hija predestinada de Ana y Joaquín, fue la redentora de la mujer, ¿qué era esta antes del cristianismo? $\mathrm{Al}$ precio de aquellas lágrimas y suspiros derramados al pie de la Cruz, como el Maestro de los maestros, ya considérese divino o humano, lo fue del hombre por la cruenta tragedia del Gólgota.

Las tormentas furiosas y las sequías devastadoras nunca fueron en El Hierro raras. Cuando en 1637 el beneficiado y vicario de esta parroquia, el licenciado D. Diego de Febres y Arteaga, instituyó un vínculo familiar, se refería en la pieza fundamental que el año de 1635 ocurrió en esta isla uno memorable: "Y habiendo yo venido de beneficiado por noviembre de 1635 sobrevino una gran avenida que se llamó el diluvio, el cual hizo mucho daño, llevándose las tierras al mar y personas». Ocho años después, en 1643, se repitió el fenómeno acuoso con tanta o mayor intensidad que antes, sembrando el pánico y la desgracia por doquiera.

Ante las tremendas consecuencias de aquel terrible aluvión, la fervorosa piedad de aquellos abuelos nuestros dirigió sus dolientes pasos hacia la pobre ermita que albergaba a la Virgen de los Reyes, ofrendándole sus más rendidas preces para que cesara el terrible temporal, lo que ocurrió luego con gran júbilo del vecindario que públicamente proclamaba que "no hubieron más desgracias por milagro de la misma Virgen", según se consignó en las actas capitulares del 
Cabildo. Este organismo, haciéndose intérprete del sentir general, no tardó en reunirse en sesión solemne el 24 de diciembre del mismo año, acordando hacer una fiesta anual perpetua a la Virgen por el 6 de enero, trasladándose a la ermita de la Dehesa para tal efecto (Libro III de Acuerdos, folio 226).

Todavía esa festividad se celebra en la lejana ermita, pero sin intervención municipal que, de haber continuado ejerciéndola, hoy correspondería al municipio de La Frontera.

Casi una centuria después, en el año de gracia de 1740, los herreños de aquel tiempo sufrian las terribles consecuencias de un conflicto antítesis del anterior. Una sequía pavorosa se cernía amenazadora sobre el desventurado suelo de nuestra isla, exponiendo a sus habitantes a morir de sed... "Se vio la patria en gravísimo conflicto", nos dice lacónicamente la escritura votiva, por lo que no pudiendo combatirlo por los medios naturales, se apeló a los recursos sobrenaturales que la ardiente fe les sugería. Acudieron a la Virgen "de muchas maravillas y prodigios" de la Dehesa, conduciéndola a mediados de enero del año siguiente a la parroquia con el fin de dedicarle un novenario rogativo.

Nosotros nos imaginamos la impresionante escena religiosa en la entonces pequeña iglesia parroquial. Todo un pueblo aflicto, sediento, orante y genuflexo, ante las benditas plantas del venerado Icono, uniendo sus preces implorantes, sus súplicas, sus gemidos en los que pondrían la pasión exaltada del delirio, a los cantos, graves y solemnes de la liturgia católica.

El 21 de enero, último día del precitado novenario, las nubecillas comenzaron su ascenso desde el mar, besando las cumbres sedientas y áridas. Los cúmulos celestes se trocaron en oscuros y sombríos nimbos, los relámpagos iluminarian el espacio, los truenos retemblarian como salvas anunciadoras de la buena nueva, gruesas gotas empezarian a caer primero, más unidas luego y con agitación violenta después. Pronto llovió a cántaros, llevando el consuelo y la alegría a todos, aquellas copiosísimas lluvias que se extendieron por toda la isla, durando algunos días. He aquí el origen del tradicional Voto de la Bajada.

Congregados en la iglesia parroquial el 26 de enero de 1741, la justicia y regimiento, el clero y los vecinos, representados por sus alcaldes pedáneos, por escritura otorgada ante el escribano público y de Cabildo, Gabriel Sánchez Frías y Magdaleno, "confesando todos deben tan saludable remedio (el de las lluvias) a la Madre de Dios de los Reyes", se comprometió el vecindario a "que cada cuatro años, que será el primero el año 1745, y de allí en adelante al mismo cómputo y respecto, pasará un Sr. beneficiado y los clérigos que arbitraren los Sres. justicia y regimiento y vecinos que no tuviesen legítimo impedimento al santuario y ermita de la Señora y, con el mayor culto y veneración, la conducirán a esta villa, que haya o no urgente necesidad, por el motivo que va relacionado". En cuanto a la fecha del traslado decía la propia escritura, cuya copia se custodia en la parroquia, que "se reserva al arbitrio de los Sres. beneficiados y Sres. justicia y regimiento, que sabrán arbitrar lo que fuere más oportuno y conveniente". Para los gastos de cera de las festividades de la $\mathrm{Ba}$ jada se obligaban los vecinos, también a perpetuidad, a contribuir anualmente con "un queso del esquilmo de su ganado en la misma forma que Dios se lo 
diere». Suscribieron la precitada escritura, entre otros clérigos, regidores y vecinos de significación, el alcalde mayor, don Juan de Ayala Barreda, su padre, el gobernador de las armas, don Pío de Espinosa Guadarrama y el beneficiado rector de la parroquia, don Cayetano Padrón de la Barreda, personaje este citado por Viera, con otro motivo en su notable historia regional.

Bien pronto, cumpliendo el voto centenario, toda la isla de El Hierro por todos sus caminos y senderos, desde todos sus caserios, desde todos sus rincones, enviará a la cumbre caldeada por un ardiente sol primaveral, sus alegres caravanas de romeros, presididas por sus santos patrones, que se desbordarán por aquellas llanuras esteparias para dar guardia de honor a la Virgen de su devoción, entre los acompasados sones de los tamboriles y flautas de sus típicos «bailarines». Y Nuestra Señora de los Reyes hará su entrada, en el año cuadragésimo cuarto de su Bajada, en la villa de Valverde, recorriendo sus calles entre los mudos homenajes de sus creyentes.

$¡ O h$, Virgen de aspecto pastoril! Yo inclino, reverente, mi cabeza ante Ti, porque Tú hablas a mi espíritu el lenguaje venerable y arcádico de las tradiciones locales, impregnadas de los más puros efluvios de la fe de mis mayores remotos y próximos... ¡Salve, Estrella de los mares!》 


\section{MiscelÁNeAs HiSTÓRICO-PALMERAS. AsunTOS GREMIALES Y DE CASTRAMETACIÓN}

[La Tarde, Santa Cruz de Tenerife, 19 de marzo de 1956, p. 4]

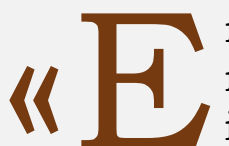

n una de nuestras vulgarizaciones históricas de las que, habitualmente, venimos publicando en este popular diario, defensor de los intereses de la provincia, La Tarde, no hace mucho tiempo dedicamos un par de artículos, si mal no recordamos, a los antiguos gremios de oficios, singularmente tinerfeños; pero ahora, repasando las no muy escasas notas históricas que, años hace, recogimos un dia sobre la isla de La Palma, nos tropezamos con un acuerdo tomado en su secular Cabildo, presidido a la sazón, por falta de teniente de corregidor, por uno de sus patricios locales, apellidado Poggio, su fecha 12 de enero de 1756, que complementan algo más el conocimiento sobre aquella institución medieval, precisamente en unos momentos en que por imperio de las ideas que ya bullian en la nueva sociedad, estaba llamada a desaparecer, una vez cumplida su misión dentro de las antiguas normas económicas, con inmediata aplicación de división del trabajo y, por ende, a la diferenciación de la muchedumbre social, en clases.

Consta en la expresada sesión cabildeña que entraron en la sala capitular Cristóbal Guerra de Oropesa y Francisco de Acosta, alcaldes del oficio de herrero; Bartolomé Felipe (?), oficial de carpintero; Policarpo de la Concepción y Pedro Méndez, alcaldes del oficio de pedrero; Matías de Brito y José Romero, que lo eran del oficio de zapatería; Francisco Vasco y Diego Melián, de los de tonelería, todos los cuales ante el Concejo palmero juraron en forma de derecho cumplir por lo tocante y perteneciente a sus respectivos oficios. En la propia acta los regidores tomaron el acuerdo de que dichos alcaldes o jefes de cada gremio cumplieran con la obligación de llevar sus respectivos pendones, acompañando a la ciudad-Concejo en sus salidas. También se notificó al antes expresado Francisco Vasco, alcalde del oficio de tonelero, para que en próxima sesión se encontrara en la sala capitular para proceder al examen de los oficiales de su oficio. De modo que, por este acuerdo, que podemos generalizar para todas las islas importantes del archipiélago, sus Cabildos tenian intervención directa tanto en la elección de maestros-jefes de cada gremio como en los exámenes en sus diversos grados de aprendices, oficiales y maestros. El gremio de los hombres de mar debió tener en La Palma, concretamente en la ciudad-capital, gran importancia a juzgar por la ermita que todavía conserva en las alturas de su marina, bajo la advocación de su patrón, San Telmo, ya que guarda muchos exvotos. Su organización debió correr pareja con el gremio de mareantes de la ciudad de Canaria.

Por último, el cronista ha podido comprobar, sobre todo en una de las ocasiones en que con menor premura realizó una investigación en el antiguo Cabildo municipal de Santa Cruz de La Palma, cuya importancia es casi paralela al de su afin lagunero, que sus libros capitulares de todo tiempo eran más minuciosos en consignar datos que sus congéneres de las demás islas, con 
gran ventaja para la investigación moderna. Tomen nota de esto, si les place, la multitud de investigadores de la Historia con que hoy cuentan nuestras islas, después de la creación en nuestra Universidad de la Facultad de Filosofia y Letras, en su sección de Historia.

Dacio Victoriano DARIAS Y PADRÓN 


\section{PENDONES Y BANDERAS ANTIGUOS}

[El Día, Santa Cruz de Tenerife, 6 de agosto de 1959, p. 3]

\section{«D}

e este para nosotros interesante tema relativo a pendones y banderas históricas hace años y con relación a nuestras islas, que por lo menos en nuestra intención son totalitarias y sin mezquindades de capilla, lo hemos abordado y con una posible independencia de juicio, sin vistas a pueriles vanidades populares, porque estos simbolos e insignas militares en el fondo son siempre respetables, cualesquiera que sea su antigüedad, entre aquellos pueblos que han sabido conservarlos como herencia sagrada de nuestros mayores. Y para el militar de vocación y no de oficio, donde entran a veces variadas nacionalidades, la bandera, como dice el tratadista militar Almirante, siempre será un simbolo sagrado y un objeto ferviente de culto, sea como sea su forma o tamaño. De la misma manera, dentro de cada pueblo cuyos habitantes estén dotados de un inteligente patriotismo local, que nunca sea agresivo para las demás poblaciones y que hagan de su amor pueblerino, basado en la familia, un sentimiento parecido al religioso, que le lleve a tener fe en los destinos futuros de su amado suelo nativo, aquellos símbolos más o menos cercanos en el tiempo, que han perfilado y ungido su pasado, tendrán que ser siempre augustos y respetables, aunque su antigüedad no sea muy remota, por la alta significación que en sí encierran. E1 empeño del citado autor desde luego lo reputamos laudable en cuanto a su intento heurístico, por lo menos, si prescindimos como queremos prescindir ahora, de sus posibles deficiencias, algo de pesadez y cierta falta de sistematización, circunstancias que disculpamos en cierto modo, ya sea por su falta de preparación en cuanto a su carencia de base técnica comercial y de un conocimiento siquiera elemental, en el campo de la historia, tanto de nuestra economía clásica como de la mundial, que tuvo sus repercusiones en las islas. Habría que conocer, además, algo de autores tales como nuestro Colmetro, cuya lectura, sin embargo, no debe aceptarse sin algunas prevenciones, hasta autores de nuestros dias especializados en la materia, publicistas que conocieron y conocen a fondo la materia; y en el detalle, épocas donde ocurrieron acontecimientos del volumen de la Reforma, descubrimientos y otras invenciones, que originaron, indudablemente, el despliegue del capital, entonces por lo general, concentrado en pocas manos, junto con aquella ingente inundación de metales preciosos, cuyo fenómeno económico causó entonces a nuestra nación, la descubridora de nuevas tierras y la proveedora de aquel acervo crematístico, su empobrecimiento y ruina.

En cada uno de los antiguos Cabildos canarios de nuestras islas mayores, sus respectivos alféreces mayores tenían el privilegio de alzar el pendón real, que es y no otra cosa su verdadera significación, en ciertas ocasiones solemnes bien limitadas, porque tales pendones no eran la clásica caja de turrones, a saber: en las proclamaciones de nuestros reyes, así como en sus exequias reales, y en la fiesta de San Cristóbal, por lo que hace a Tenerife. Parecido ocurrido pasaba en Gran Canaria, pero en La Palma consta que el pendón real se sacaba, además de en las anteriores solemnidades de reyes y fiesta del 
patrón, allí de la Santa Cruz, aniversario de la conquista, en la del Corpus Christi.

En cuanto a la familia Valcárcel, que poseía el alferazgo mayor y residia de ordinario en el lugar, después villa, de La Orotava, guardaba en su propia casa el citado pendón, pero el Cabildo palmero, por ser propiedad suya, lo conservaba en su sala de sesiones, cuyo derecho litigó con aquel alférez mayor. Hoy es un venerable y sagrado muñón enrollado en su asta. La casa de Valcárcel cesó en su honorífico oficio concejil en el último tercio del siglo XVIII, entre otras causas, porque en cierta real cédula se disponía a rajatabla la precisa residencia en la capitalidad lagunera, razón por la cual, todos los que tenían oficios de regiduría y residian en distintos lugares de la isla perdieron automáticamente sus oficios.

Nosotros hemos estudiado personalmente las armas y blasones que hoy todavía conservan bordados en sus respectivos damascos rojos, y de ellos hemos sacado la consecuencia de su real antigüedad, que estamos seguros no diferirá de la opinión de cualquier experto en Heráldica. No hemos, pues, de repetir aquí lo que hace años expusimos acerca de la antigüedad real de tales reliquias, siempre denominados "pendones reales" y no de otra manera, como figuran en sus antiguas actas capitulares.

Tales pendones reales, como propios que eran del rey y no de los municipios en las islas menores, eran pendones del señor territorial, como los de Lanzarote y Fuerteventura, que conocemos - eran vivas representaciones entonces de la persona augusta del soberano y no de la nación, como hoy sucede a partir del régimen constitucional, cuando las monarquias cesaron de ser patrimoniales-. De modo que hoy los mismos reyes, primeros súbditos de la nación, se inclinan ceremoniosamente ante las banderas nacionales, como los demás connacionales.

Tenía el Cabildo de Tenerife, fuera del pendón real, la llamada "bandera general", si bien sospechamos que andando los años, cayó en desuso, aunque se trata de un caso que pudiera hoy restablecerse con todos sus honores, por el Cabildo Insular. Era de tafetán y sus colores, blanco, azul y amarillo, con una cruz de gules. Ya no tenía asta, cuando en 17 de enero de 1561 se hizo cargo de la misma, al tomar posesión de su cargo de alférez mayor y regidor, el capitán Francisco de Valcárcel. Ocho dias más tarde, el 25 del expresado mes y año, dicho alférez mayor recibió de manos del mayordomo del Cabildo, Juan Sánchez de Zambrana, "el estandarte e guión real que la ysla tiene, el cual estandarte tiene de un cabo la ymagen de Nra. S. ${ }^{a}$ de Candelaria e de la ptra pe. (parte) las armas reales y la punta larga de tafetán -no habla de damasco- colorado; y el guión, las armas reales de Castilla bordado de oro o seda e plata y guarnysión amarillan.

Como detalle curioso, hemos de exponer aquí que el mismo capitán Francisco de Valcárcel, titulándose alférez general y regidor de la isla, otorgó poder en el entonces lugar de La Orotava, ante el escribano público Nicolás de Cala, al señor Bernardino Justiniano, regidor, para que en su nombre "pueda sacar y saque el día del señor San Xpval. el pendón rreal desta ysla». Su fecha, 26 de julio de 1598. 
Todo cuanto hemos consignado en esta vulgarización histórica, ciñéndonos estrictamente al discurso X del clásico Cabrera de Córdoba, que a su vez lo toma de Polibio, sobre que "el ánima de la Historia es la verdad", hace bastante tiempo, cuando realizamos una investigación a fondo en el rico archivo cabildeño, que custodia el Ayuntamiento lagunero, cuyos legajos no bien cuidados ni tampoco ordenados, alli se conservan como Dios quiere, se refieren a la inspección militar, legajo primero, número 5 . Y digamos con el obispo de Hipona: "Veritas est id quod est»." 